San Jose State University

SJSU ScholarWorks

Mineta Transportation Institute Publications

$12-2020$

\title{
Toward a Guide for Smart Mobility Corridors: Frameworks and Tools for Measuring, Understanding, and Realizing Transportation Land Use Coordination
}

\author{
Bruce Appleyard \\ San Diego State University \\ Jonathan Stanton \\ San Diego State University \\ Chris Allen \\ San Diego State University
}

Follow this and additional works at: https://scholarworks.sjsu.edu/mti_publications

Part of the Infrastructure Commons, and the Transportation Commons

\section{Recommended Citation}

Bruce Appleyard, Jonathan Stanton, and Chris Allen. "Toward a Guide for Smart Mobility Corridors:

Frameworks and Tools for Measuring, Understanding, and Realizing Transportation Land Use Coordination" Mineta Transportation Institute Publications (2020). https://doi.org/10.31979/ mti.2020.1805

This Report is brought to you for free and open access by SJSU ScholarWorks. It has been accepted for inclusion in Mineta Transportation Institute Publications by an authorized administrator of SJSU ScholarWorks. For more information, please contact scholarworks@sjsu.edu. 


\section{SJSU UNIVSESITYY}

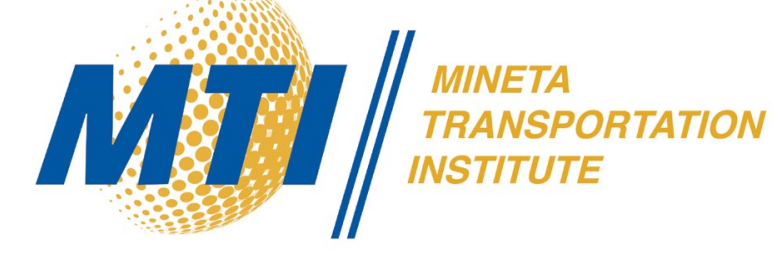

Toward a Guide for Smart Mobility Corridors:

Frameworks and Tools for Measuring, Understanding, and Realizing Transportation Land Use Coordination

Bruce Appleyard, PhD

Jonathan Stanton

Chris Allen

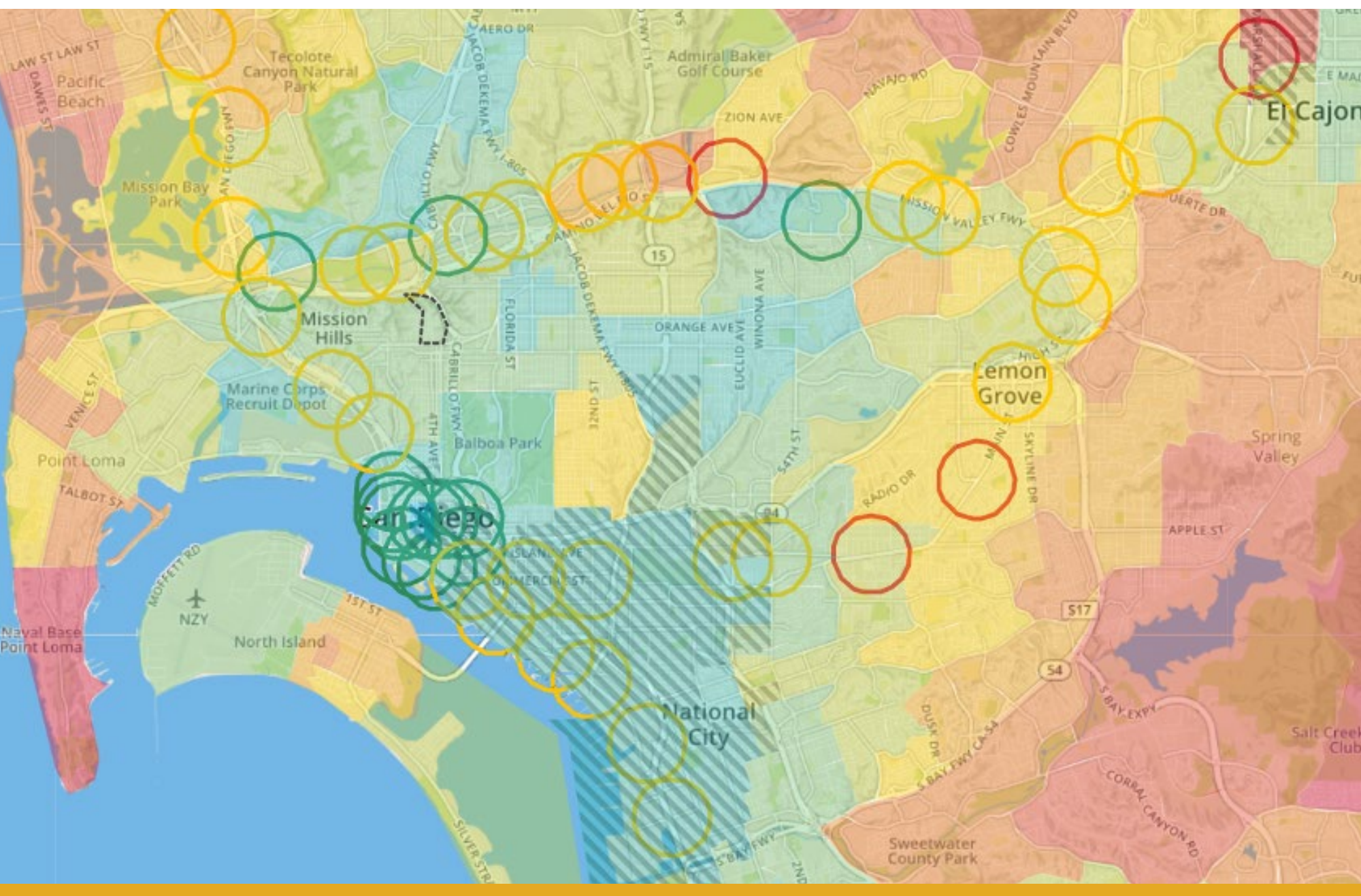




\section{MINETA TRANSPORTATION INSTITUTE}

Founded in 1991, the Mineta Transportation Institute (MTI), an organized research and training unit in partnership with the Lucas College and Graduate School of Business at San José State University (SJSU), increases mobility for all by improving the safety, efficiency, accessibility, and convenience of our nation's transportation system. Through research, education, workforce development, and technology transfer, we help create a connected world. MTI leads the Mineta Consortium for Transportation Mobility (MCTM) funded by the U.S. Department of Transportation and the California State University Transportation Consortium (CSUTC) funded by the State of California through Senate Bill I.MTI focuses on three primary responsibilities:

\section{Research}

MTI conducts multi-disciplinary research focused on surface transportation that contributes to effective decision making. Research areas include:active transportation; planning and policy; security and counterterrorism; sustainable transportation and land use; transit and passenger rail; transportation engineering; transportation finance; transportation technology; and workforce and labor. MTI research publications undergo expert peer review to ensure the quality of the research.

\section{Education and Workforce Development}

To ensure the efficient movement of people and products, we must prepare a new cohort of transportation professionals who are ready to lead a more diverse, inclusive, and equitable transportation industry. To help achieve this, MTI sponsors a suite of workforce development and education opportunities. The Institute supports educational programs offered by the Lucas Graduate School of Business: a Master of Science in Transportation Management, plus graduate certificates that include High-Speed and Intercity Rail Management and Transportation Security Management. These flexible programs offer live online classes so that working transportation professionals can pursue an advanced degree regardless of their location.

\section{Information and Technology Transfer}

MTI utilizes a diverse array of dissemination methods and media to ensure research results reach those responsible for managing change. These methods include publication, seminars, workshops, websites, social media, webinars, and other technology transfer mechanisms. Additionally, MTI promotes the availability of completed research to professional organizations and works to integrate the research findings into the graduate education program. MTI's extensive collection of transportation-related publications is integrated into San José State University's world-class Martin Luther King, Jr. Library.

\section{Disclaimer}

The contents of this report reflect the views of the authors, who are responsible for the facts and accuracy of the information presented herein. This document is disseminated in the interest of information exchange. MTl's research is funded, partially or entirely, by grants from the U.S. Department of Transportation, the U.S. Department of Homeland Security, the California Department of Transportation, and the California State University Office of the Chancellor, whom assume no liability for the contents or use thereof. This report does not constitute a standard specification, design standard, or regulation. 
REPORT 20-54

\title{
TOWARD A GUIDE FOR SMART MOBILITY CORRIDORS: FRAMEWORKS AND TOOLS FOR MEASURING, UNDERSTANDING, AND REALIZING TRANSPORTATION LAND USE COORDINATION
}

\author{
Bruce Appleyard, $\mathrm{PhD}$ \\ Jonathan Stanton \\ Chris Allen
}

December 2020

A publication of

Mineta Transportation Institute

Created by Congress in 1991

College of Business

San José State University

San José, CA 95192-0219 


\section{TECHNICAL REPORT DOCUMENTATION PAGE}

1. Report No. 20-54

4. Title and Subtitle

Toward a Guide for Smart Mobility Corridors: Frameworks and Tools for Measuring, Understanding, and Realizing Transportation Land Use Coordination

7. Authors

Bruce Appleyard, PhD, https://orcid.org/0000-0003-2105-8079

Jonathan Stanton, https://orcid.org/0000-0003-3071-0727

Chris Allen, https://orcid.org/0000-0002-3336-2601

9. Performing Organization Name and Address

Mineta Transportation Institute

College of Business

San José State University

San José, CA 95192-0219

12. Sponsoring Agency Name and Address

California Department of Transportation

1120 N Street

Sacramento, CA 95814
3. Recipient's Catalog No.

5. Report Date

December 2020

6. Performing Organization Code

8. Performing Organization Report CA-MTI-1805

10. Work Unit No.

11. Contract or Grant No. 65A0660

13. Type of Report and Period Covered Final Report

14. Sponsoring Agency Code

\section{Supplemental Notes}

DOI: 10.31979/mti.2020.1805

\section{Abstract}

The coordination of transportation and land use (also known as "smart growth") has been a long-standing goal for planning and engineering professionals, but to this day it remains an elusive concept to realize. Leaving us with this central question -- how can we best achieve transportation and land use coordination at the corridor level?

In response, this report provides a review of literature and practice related to sustainability, livability, and equity (SLE) with a focus on corridor-level planning. Using Caltrans' Corridor Planning Process Guide and Smart Mobility Framework as guideposts, this report also reviews various principles, performance measures, and place typology frameworks, along with current mapping and planning support tools (PSTs). The aim being to serve as a guidebook that agency staff can use for reference, synergizing planning insights from various data sources that had not previously been brought together in a practical frame.

With this knowledge and understanding, a key section provides a discussion of tools and metrics and how they can be used in corridor planning. For illustration purposes, this report uses the Smart Mobility Calculator (https://smartmobilitycalculator. netlify.app/), a novel online tool designed to make key data easily available for all stakeholders to make better decisions. For more information on this tool, see https://transweb.sjsu.edu/research/1899-Smart-Growth-Equity-Framework-Tool. The Smart Mobility Calculator is unique in that it incorporates statewide datasets on urban quality and livability which are then communicated through a straightforward visualization planners can readily use.

Core sections of this report cover the framework and concepts upon which the Smart Mobility Calculator is built and provides examples of its functionality and implementation capabilities. The Calculator is designed to complement policies to help a variety of agencies (MPOs, DOTs, and local land use authorities) achieve coordination and balance between transportation and land use at the corridor level.

\section{Key Words}

Transit, corridor, smart growth, transit oriented development, land use

19. Security Classif. (of this report) Unclassified

\section{Distribution Statement}

No restrictions. This document is available to the public through The National Technical Information Service, Springfield, VA 22161 


\title{
Copyright $\odot 2020$ \\ by Mineta Transportation Institute \\ All rights reserved
}

DOI: 10.31979/mti.2020.1805

\author{
Mineta Transportation Institute \\ College of Business \\ San José State University \\ San José, CA 95192-0219 \\ Tel: (408) 924-7560 \\ Fax: (408) 924-7565 \\ Email: mineta-institute@sjsu.edu
}

transweb.sjsu.edu 


\section{ACKNOWLEDGMENTS}

The authors wish to thank the Mineta Transportation Institute, the US Department of Transportation, and Caltrans for their gracious support, especially Ann Mahaney and her staff at Caltrans. We would also like to acknowledge the work of particular researchers and collaborators, including David Reinke, Christopher Ferrell, Alexander Frost, Eduardo Cordova, Caleb Schroeder, and Annapurna Singh.

The authors thank Editing Press, for editorial services, as well as MTI staff, including Executive Director Karen Philbrick, PhD; Deputy Executive Director Hilary Nixon, PhD; Graphic Designer Alverina Eka Weinardy; and Communications and Operations Manager Irma Garcia. 


\section{TABLE OF CONTENTS}

$\begin{array}{lr}\text { EXECUTIVE SUMMARY } & 1\end{array}$

$\begin{array}{ll}\text { I. Introduction } & 3\end{array}$

II. Understanding Sustainability, Livability, \& Equity 4

History of the Term "Sustainable Development" 4

Defining Urban Sustainability $\quad 5$

Defining Livability: The transportation/Land Use, Smart Growth, \&

Defining Equity: Toward an Equitable Livability and Smart Growth 8

Section Conclusion $\quad 8$

III. Background and Overview of Planning Support Tools (PSTs) 9

Related Academic Work $\quad 9$

A review of Practitioner Planning Support Tools To Help Measure, Understand, and Realize Sustainability, Livability, and Equity Outcomes 10

$\begin{array}{ll}\text { Section Conclusion } & 12\end{array}$

IV. Livability and Smart Mobility Calculators 14

Introduction and Background 14

Smart Mobility Calculator: Overview 17

$\begin{array}{ll}\text { The Uses of the Smart Mobility Calculator } & 21\end{array}$

V. Illustrative Examples of the Smart Mobility Calculator in Action 23

Caltrans' New Corridor Planning Process 23

VI. New Environmental Regulations for Project Development Review: Using the Smart Mobility Calculator for VMT instead of Level of Service -An Illustrative Example

How Using VMT Instead of Level of Service Helps Transform Our Auto-

Mobility Paradigm $\quad 27$

How the Smart Mobility Calculator Can Help with VMT Analysis for the California Environmental Quality Act (CEQA) 28

TOD Atlas: The Equity of Urban Quality Around Train Stations 30

VII. Caltrans' Smart Mobility Framework Implementation Project Case Study 31

Implementation Frameworks to Coordinate Transportation and Land Use in Decision-Making Processes

Working with Key Professionals: Joint Stakeholder Meeting with SANDAG and Caltrans 
VIII. Conclusion

Appendix

Going Forward: A Framework for Measuring, Understanding, and Realizing Transportation and Land Use Coordination

Abbreviations and Acronyms

Endnotes

52

Bibliography

53

About the Authors

62 


\section{LIST OF FIGURES}

1. Operationalization of the Livability Principles of the 2009 HUD/DOT/EPA Partnership for Sustainable Communities

2. A Screenshot of the Opportunities Atlas, Produced by Opportunity Insights at Harvard University

3. Operationalizing the 2009 Livability Principles of the HUD/US-DOT/EPA Sustainable Communities Partnership

4. Livability Calculator for the Handbook for Building Livable Transit Corridors

5. An Example of How the Performance Radar Graphic from the Livability Calculator can be Merged with the Smart Mobility Calculator

6. The Location Efficient Neighborhood Design

7. Average VMT per Capita Using the Location Efficient Neighborhood Design

8. The Caltrans Corridor Planning Process

9. The SMF Place Types Can Also be Displayed in the Smart Mobility Calculator and Used in the Caltrans Corridor Planning Process

10. Selecting a Corridor in the Smart Mobility Calculator, then Inputting the FIPS Code Data into the Livability Calculator's Input Sheet

11. Corridor Performance Displayed in the Livability Performance Sheet on the Livability Calculator

12. Displaying Policy Options in the Handbook for Building Livable Transit Corridors via the Livability Calculator's Strategy Summary Sheet

13. SB 743 Visualization and Examples in Smart Mobility Calculator

14. Smart Mobility Calculator Used to Determine SB 743 Compliance

15. Light Rail Station Performance and 1/2-mile Overlay in the Smart Growth Calculator

16. Smart Mobility Framework

17. Metro Place-Type Framework

18. Metro Place-Type Framework 
19. Accessibility Clusters of the Metro Place-Type Framework in the Hawthorne Study Area

20. Maps and Legend Based on Location Efficient Neighborhood Design

21. Location Efficient/Neighborhood Design Framework and Smart Growth Calculator

22. Basic Framework for Transportation and Land Use Decisions Using the LEND Clusters Concept

23. Conceptual Meta-View of the Ecosystem of Performance Measures, Their Production, and How They Can be Applied

24. Joint Stakeholder Meeting with Caltrans and SANDAG 


\section{LIST OF TABLES}

1. Sample of Public Sustainability and Livability Planning Tools

2. The Twelve Metrics of the Livability Calculator: Operationalizing the Livability Principles of the HUD/USDOT/EPA Sustainable Communities Partnership

3. The Metrics of the Smart Mobility Calculator

A1. Recommended Performance Metrics 


\section{EXECUTIVE SUMMARY}

The coordination of transportation and land use (also known as "smart growth") has been a long-standing goal for planning and engineering professionals, but to this day it remains an elusive concept to realize. Leaving us with this central question -- how can we best achieve transportation and land use coordination at the corridor level?

In response, this report provides a review of literature and practice related to sustainability, livability, and equity (SLE) with a focus on corridor-level planning. Using Caltrans' Smart Mobility Framework and Corridor Planning Process Guide as guideposts, this report also reviews various principles, performance measures, and place typology frameworks, along with current mapping and planning support tools (PSTs). The aim being to serve as a guidebook that agency staff can use for reference, synergizing planning insights from various data sources that had not previously been brought together in a practical frame.

With this knowledge and understanding, a key section provides a discussion of tools and metrics and how they can be used in corridor planning. For illustration purposes, this report uses the Smart Mobility Calculator (https://smartmobilitycalculator.netlify.app/), a novel online tool designed to make key data easily available for all stakeholders to make better decisions. For more information on this tool, see https://transweb.sjsu.edul research/1899-Smart-Growth-Equity-Framework-Tool. The Smart Mobility Calculator is unique in that it incorporates statewide datasets on urban quality and livability which are then communicated through a straightforward visualization planners can readily use.

Core sections of this report cover the framework and concepts upon which the Smart Mobility Calculator is built and provide examples of its functionality and implementation capabilities. The Calculator is designed to complement policies to help a variety of agencies (MPOs, DOTs, and local land use authorities) achieve coordination and balance between transportation and land use.

Specifically, this report presents the following:

- A review of the literature and practice related to sustainability, livability and equity

- A brief review of Planning Support Tools (PSTs).

- A discussion of measurement and action/policy guidance frameworks, as well as how they can be applied through the use of an accessible online tool, the Smart Mobility Calculator to corridor level planning.

- A discussion of the development of a decision making framework, using the Caltrans' Smart Mobility Framework Implementation Project as a case study.

- This report shows how the Calculator can be used in a variety of situations towards better transportation/land use coordination, especially at the corridor level. 
Such a planning and evaluation framework must be able to: (1) help understand what is important to measure and analyze in current conditions and future scenarios; (2) help create context-sensitive and inclusive processes to guide policy actions; and (3) screen, prioritize, and mediate strategies in support of transportation and land use coordination-which could be defined as increasing a diverse and complementary set of choices and opportunities for individuals to pursue toward the achievement of their desired quality of life. 


\section{INTRODUCTION}

The umbrella term Transportation Land Use Coordination (TLC) is a widely recognized approach for achieving what is often referred to as "smart growth" (Cervero 2001; Moore, Thorsnes, and Appleyard, 2007; Appleyard et al. 2016a; Appleyard et al., 2019). However, in the absence of substantial institutional changes to transportation and land use that allows stakeholders to work in a truly coordinated fashion, we are left to seek methods with data, performance measurement, and policy guidance frameworks to achieve more holistic TLC approaches. As discussed in Appleyard et al. (2014, 2016, 2019), transportation agencies, such as Caltrans, can best achieve sustainable, livable, and equitable outcomes when they work in concert with others, especially local land use agencies. Therefore, a major focus of this report is to help guide staff in state DOTs, regional MPOs, and local land use authorities to develop frameworks to measure performance of corridors in terms of their transportation/ land use coordination (TLC), be able to understand what those measurements mean, and then guide actions, decisions, and policies toward realizing stronger TLC.

Here are some givens that may further our understanding of what is happening. First, as a transportation agency, Caltrans, and most other DOTs work at a much broader spatial scale than most land use agencies_-primarily at the regional/corridor levels. Second, as a transportation agency, Caltrans interacts, either directly or indirectly, with many other agencies and can engage, at some level, with their core activities, whether it be land use, housing, public health, environmental quality, and/or economic development. Therefore, Caltrans is in an ideal position to reach out and work with the other agencies (as a sort of ambassador) toward realizing a higher level of coordination of a variety of government activities at the corridor level. A key opportunity is that Caltrans can offer a forum for coordinated governance at the corridor scale--a scale critical for the coordination of transportation and land use, around which agencies can work together. To this end, Caltrans and other DOTs need solid frameworks and tools to measure the TLC performance of urban environments, as well as the ability to understand what the measures mean and then the ability to put that knowledge into practice. Caltrans has made significant strides toward TLC through its Smart Mobility Framework efforts. This work build on this work.

To help Caltrans and other DOTs work with and refine various measurement and policy guidance frameworks, this report builds on a variety of academic research from fields such as urban planning, geography, and operations research. As part of the development of the Smart Mobility Calculator, this report also draws on literature and practical experience related to planning support tools (PSTs). ${ }^{1}$

A key aim of this report is to bring the coordination of transportation and land use by the loosely organized collection of actors and agents (MPOs, DOTs, and local land use authorities, etc.) into coordination through new measurement and policy guidance frameworks to be applied through a variety of planning support tools (PSTs). To illustrate the applications of the various frameworks, this report uses the Smart Mobility Calculator (https://smartmobilitycalculator. netlify.app/), an online tool designed by the authors to make key data easily available to all stakeholders so they can more readily make coordinated decisions. Absent a major restructuring of our transportation and land use institutions, and the scales on which they operate, adopting new frameworks to measure and understand transportation and land use coordination (TLC) is the first step toward realizing it. 


\section{UNDERSTANDING SUSTAINABILITY, LIVABILITY, \& EQUITY}

Sustainability, livability, and equity are long-standing societal objectives, but they remain elusive concepts in policy and practice. And while a number of related performance measures and tools have been developed over the past two decades, there appears little progress toward a generally accepted set of measures that can inform planning and policy decisions.

This report provides a review of literature and practice to help inform the preliminary development of a measurement, evaluation, and policy guidance framework based on sustainability, livability, and equity. The review will give context to the concepts and foundational measurements and calculations of the Livability and Smart Mobility Calculators.

The report then works toward integrating Smart Mobility principles, concepts, and performance measures in accordance with the Smart Mobility Framework (SMFs) as described in Caltrans' Smart Mobility 2010: A Call to Action for the New Decade (Caltrans, 2010) as well as the 2020 Corridor Planning Process Guide (Caltrans 2020). Both these projects were conducted in response to several state-level mandates to reduce greenhouse gas emissions from the transportation sector, as well as to enhance California's environment, economy, and equity (the $3 \mathrm{Es}$ ). The analysis and recommendations in this chapter are also based on a joint project between Caltrans, the South Bay Cities Council of Governments (SBCCOG), the Los Angeles County Metropolitan Transportation Authority (LA MTA), and SCAG to implement the SMF in a planning project for the South Bay Cities area of LA-this project merges SMF place types and Metro's Accessibility Clusters, as presented in LA MTA's Metro Countywide Sustainability Planning Policy (CSPP). A key goal of the work presented in this report is to inform and assist Caltrans' efforts on a variety of issues, including complete streets and corridor planning, and with regional Sustainable Communities Strategy (SCS) as part of California's climate action initiatives.

\section{HISTORY OF THE TERM “SUSTAINABLE DEVELOPMENT”}

The concept of sustainability as applied to human settlements and activities was first popularized in the 1970s with the publication of The Limits of Growth (Meadows et al. 1972) wherein the authors argued that a "sustainable" condition of ecological and economic stability was possible if significant changes were made to industrial and developing economies. Though the idea of sustainability had long been discussed in terms of biological and ecological systems, its application to human settlements was new, but it soon became common in academic and popular publications (see Beatley 1995; Wheeler 2000; Jepson 2001). The "Brundtland Report," 2 published in 1987, provided the definition of sustainable development that has been most widely cited and used ever since:

Sustainable development is development that meets the needs of the present without compromising the ability of future generations to meet their own needs. (World Commission on Environment and Development 1987, p. 43)

This definition has been criticized as being anthropocentric (i.e., overly concerned with humans) and subjective (how does one objectively measure "needs"?). Many other definitions have been offered, but most of them have been problematic in fostering agreement on what 
specific concepts or indicators to measure and how to do so in a way that is widely accepted (see Wheeler 2000 and Jepson 2001 for more detailed discussions of the history and definition of sustainability). Despite the definitional problems, there is growing consensus that sustainability has three main components: economic sustainability, environmental sustainability, and socially equitable sustainability. ${ }^{3}$

\section{DEFINING URBAN SUSTAINABILITY}

According to the 1998 NSF Report on Urban Sustainability, ${ }^{4}$ in order to understand urban sustainability, it is important to examine the process of urbanization within the context of dynamic and complex social, economic, political, and ecological processes producing sustainable or unsustainable urban landscapes and outcomes. The report goes on to suggest that research should be designed around an extensive program of comparative case studies, focusing on long-term analyses of human-environment dynamics at selected sites. Therefore, while there are numerous ways of achieving sustainability, it appears that performance evaluation frameworks should be at the center of how different agencies can work together through their fostering of a common understanding of what the evaluations mean and what policy actions need to be taken. ${ }^{5}$

\section{DEFINING LIVABILITY: THE TRANSPORTATION/LAND USE, SMART GROWTH, \& LIVABILITY CONNECTION}

For years, top researchers in urban and transportation planning have focused on developing effective strategies for transportation/land use coordination (TLC) and smart growth to achieve a wide range of goals associated with livability (Appleyard, 2005; Moore et al., 2007; Appleyard, 2011b; Cervero, 2003, 2001). In a 2001 speech to the Australian Planning Association, Robert Cervero described the fundamental elements needed to advance "smart growth," directly characterizing this as the coordination between transportation and land use planning (Cervero, 2003, 2001). In 2005, Susan Handy published an article in the International Regional Science Review in which she reviewed recent research on the transportation and land use connection, which further tied TLC to smart growth (Handy, 2005). At its core, transportation and land use coordination (TLC) is an integrative concept that ties together access through both (a) mobility via transportation policy, and (b) proximity via land use policy (Cervero, 2000; Cervero et al., 1999; El-Geneidy and Levinson, 2006; Levine et al., 2012, 2009; Levinson, 1998; Wagner and Caves, 2012). Therefore, TLC can be viewed as a key component of best planning practices connected to the provision of access to "livability opportunities" (Appleyard et al., 2014; US EPA, 2016; Moore et al., 2007) and "smart growth" (Cervero, 2000 ) by both practitioners and academics alike. For example, in Chapter 11 of Wagner and Cave's book Community Livability, Dr. Ruth Steiner establishes the EPA's ten smart growth principles as a mainstay of livability planning operating through transportation and land use coordination. Along these lines, there is a strong resemblance between the six livability principles of the HUD/US-DOT/EPA Sustainable Communities Partnership (SCP), outlined in the next paragraph and the EPA's ten smart growth principles (US EPA, 2016; Wagner and Caves, 2012). 
However, in large part due to the institutional imbalances between the transportation and land use sectors (Appleyard, 2005, 2011; Appleyard et al., 2014; Moore et al., 2007), smart growth and TLC have been hard to achieve in the United States. To illustrate this point, the reader should recognize how the transportation sector, in comparison to the land use sector, has a powerful vertical public/private organization that can effectively coordinate technical expertise and programmatic knowledge to both fund and deliver projects, from road to rail transit. In contrast, land use decision making follows a much more complex, multifaceted, and loosely coordinated horizontal structure of actors including local governments, developers, real estate agents, financial institutions, community members, and advocates, with interests ranging from pro-smart-growth to not-in-my-backyard (NIMBY) sentiments. This mismatch, or imbalance, between the organizational capacity and wherewithal of these two sectors to deliver and coordinate their activities can be referred to as the transportation-land use imbalance and/or disconnect (Appleyard, 2005, 2011; Appleyard et al., 2014; Appleyard et al., 2019; Moore et al., 2007).

In response, this work endeavors to rebalance and re-integrate this disconnect through effective performance measurement frameworks and policy responses that elevate land use and urban design to be conducted at a more regional and corridor perspective, putting them on par with the scale at which we plan our transportation.

\section{Frameworks for Evaluating Smart Growth, Transportation Land Use Coordination, Sustainability, Livability, and Equity}

Research and practices focused on combining transportation land use coordination with livability reached an important milestone in 2009, when a comprehensive definition of livability was adopted by the Secretaries of Housing and Urban Development (HUD), the US Department of Transportation (USDOT), and the Environmental Protection Agency (EPA) through their Sustainable Communities Partnership (SCP). In 2016, a National Academies of Sciences project was completed that worked to better operationalize these six principles for measurement, analysis, and policy guidance through an online Smart Mobility Calculator and A Livability Calculator for the Handbook for Building Livable Transit Corridors (Appleyard et al., 2018, 2016; Ferrell et al., 2016). The Caltrans Smart Mobility Framework Principles are also provided (on the right). The similarities between all three are important to recognize. See Figure 1. 


\section{Livability Principles: \\ 2009 Partnership for Sustainable \\ Communities (HUD/DOT/EPA) \\ PARTNERSHIP FOR \\ Sustainable Communities $\longrightarrow$ \\ Livability PRINCIPLES \\ Operationalized \\ Livability PRINCIPLES \\ High-quality transit, walking, and bicycling opportunities

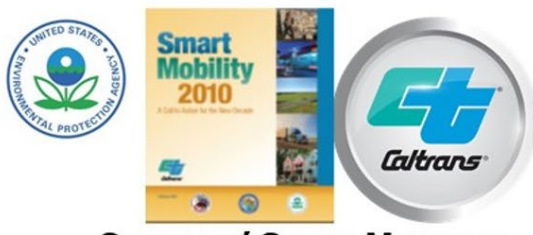 \\ Caltrans' SMARt Mobility FRAMEWORK

\begin{tabular}{|c|c|c|}
\hline Provide more transportation choices $\Longrightarrow$ & $\begin{array}{l}\text { High-quality transit, walking, and } \\
\text { bicycling opportunities }\end{array}$ & Reliable Mobility \\
\hline $\begin{array}{c}\text { Promote equitable and affordable } \\
\text { housing }\end{array}$ & $\begin{array}{l}\text { Equitable and affordable housing } \\
\text { near transit }\end{array}$ & Social Equity \\
\hline Enhance economic competitiveness $\Longrightarrow$ & $\begin{array}{c}\text { Transit-accessible economic } \\
\text { opportunities }\end{array}$ & Robust Economy \\
\hline Support existing communities & $\begin{array}{c}\text { Vibrant and accessible community, } \\
\text { cultural, and recreational } \\
\text { opportunities }\end{array}$ & Location Efficiency \\
\hline $\begin{array}{l}\text { Coordinate and leverage } \\
\text { federal policies and investments }\end{array}$ & $\begin{array}{l}\text { Effective corridor government and } \\
\text { social services }\end{array}$ & Environmental Stewardship \\
\hline $\begin{array}{l}\text { Value communities and } \\
\text { neighborhoods }\end{array}$ & $\begin{array}{l}\text { Healthy, safe, walkable transit } \\
\text { corridor neighborhoods }\end{array}$ & Health and Safety \\
\hline
\end{tabular}

Overall, the detailed language reveals how federal and state officials, and arguably many other professionals, were combining concepts of livability with concepts of smart growth, and, by extension, transportation/land use coordination. From previous work, the authors developed a framework where the measure of urban quality, or transportation/land use coordination (TLC), is determined by what the authors refer to as "livability opportunities" (affordable housing; presence of jobs; and safe, accessible walkability) (Appleyard et al., 2014; Appleyard et al., 2016). These opportunities can then be converted into quality of life outcomes, which can include things like health, safety, social inclusion, emission reductions, and so on (Appleyard et al., 2014; Appleyard et al., 2016).

These findings are also consistent with other previous studies linking higher levels of built environment performance, in terms of smart growth and TLC, to health outcomes. For example, several articles find that more compact communities are associated with lower traffic collision rates (Ahangari et al., 2017). Other studies show a connection between transit service, ridership, and improvements in traffic safety (Litman, 2016; Stimpson et al., 2014). Additionally, scholars have examined the relationship between greater walking, bicycling, and transit access and increased public health benefits from greater physical activity (Frederick et al., 2018; Lachapelle, 2010; Lachapelle and Frank, 2009; Sallis et al., 2016). Another recent study by Hamidi et al. (2018) found that life expectancy was significantly higher in compact rather than sprawling counties in the US, but the causal mechanisms are still unclear. Finally, there are new studies indicating how more compact and multimodal built environments increase economic mobility (Ewing et al., 2016; Frederick and Gilderbloom, 2018). 


\section{DEFINING EQUITY: TOWARD AN EQUITABLE LIVABILITY AND SMART GROWTH}

In measuring and understanding social equity, we need to first measure (a) the access to opportunities (jobs, schools, transport, etc.), (b) vulnerabilities (crime, education levels, quality of schools), and (c) determine whether there is an inequitable distribution based on socio-economic backgrounds to either the access to opportunities or exposure to these vulnerabilities. However, to enact policies, we likely will need an ethical framework to ensure livability achievement is equitable.

It is important to understand that what we value determines what we measure-what we measure determines how we understand problems. Therefore, what we value and measure determines the solutions that become physically manifest in our environments. So we need to examine what we value and how we measure, understand the problems, and then realize solutions. This is the domain of ethics. Therefore, rather than embracing one monolithic definition of livability, there is a need for a theoretical moral framework to measure, understand, and judge activities toward an equitable and just standard for livability achievement through a set of clear, concise, and easily applicable principles and approaches toward the realization of an ethical livability. In sum, we need livability ethics.

Upon review of all definitions of livability and smart growth (Appleyard et al., 2014; Appleyard, B. \& Appleyard, D. 2020), the authors have defined ethical and equitable livability and smart growth as:

People's easy and equitable access to opportunities they can readily pursue for their desired quality of life-

Prioritizing the needs of society's less powerful and most vulnerable, placing highest value on people's humanity, at rest and in motion, and working to overcome any past, present, or future forces of oppression.

With this maxim in mind, and our methods for measuring and understanding social inequities outlined above, we can stand a better chance of realizing an equitable livability/smart growth. To achieve this, professionals will need to be prepared to mediate between livability pursuits in conflict to prioritize the needs of society's less powerful and most vulnerable.

\section{SECTION CONCLUSION}

In sum, these six livability principles, the operationalized principles, and the Smart Mobility Framework Principles all reflect normative best planning practices related to smart growth, new urbanism, and transportation and land use coordination (TLC). As measures of urban quality that follow these principles can hopefully secure a spectrum of livability opportunities, we can, in turn, achieve a range of sustainability, livability, and equity outcomes for a greater number of people (Appleyard et al., 2014; US EPA, 2016)_all key goals of this research. 


\section{BACKGROUND AND OVERVIEW OF PLANNING SUPPORT TOOLS (PSTS)}

Before going into more detail about the Livability and Smart Mobility Calculators, this report first provides a review of the literature and practical applications of planning support tools (PSTs). Planning support tools (also called planning support systems) are computer-based applications that assist in urban planning activities by providing access to essential data, models, and spatial analysis methods (Geertman and Stillwell, 2004). These tools have transformed the ways planning is conducted by improving efficiency and reducing the complexity of planning-related tasks (Exner, 2015). Though impactful, planning support tools are not without their shortcomings. For example, a survey conducted by Vonk et al. (2005) suggests that a lack of awareness and experience with planning support systems is a significant hurdle for widespread adoption of these tools. Subsequent work by Vonk and Geertman (2008) recommends that planning support tools should emphasize accessibility to ensure that they are put into practice.

\section{RELATED ACADEMIC WORK}

To help Caltrans work with and refine various measurements and policy guidance frameworks, this work builds on a variety of academic sources from fields such as urban planning, geography, and operations research. Furthermore, as the authors are looking to exploratory web mapping applications, this project also aligns heavily with research on web GIS, geovisualization, and GeoDesign.

Along these lines, Jiang et al. (2003) provided an early demonstration of how Internet-based geovisualization applications can support planning-related decision making. More recently, scholars have shown how the rise of new data sources and GIS technologies has allowed for the creation of more powerful geovisualization and web GIS tools that allow researchers to model and explore urban environments (Yin, 2015). GeoDesign is also a new and exciting research and development area that employs an interdisciplinary approach combining GIS with urban planning to design projects at community, regional, and sub-regional scales (Steinitz, 2012). GeoDesign tools are often specifically geared toward improving sustainability in urban areas (Steinitz, 2012; Dangermond, 2010).

Finally, this project builds upon work in multi-criteria decision analysis (MCDA). The goal of this field is to create tools and strategies to help decision makers, planners, and policy makers better understand the potential outcomes of projects by revealing a wide variety of relevant factors for review (Malczewski, 2006). MCDA has been widely promoted as a scenario testing and design tool that guides decision making in order to attain more environmentally sustainable communities (Cinelli et al., 2014; Pohekar and Ramachandran, 2004). MCDA is often tightly coupled with GIS, as mapping tools and methodologies are proving essential in evaluating and understanding relevant criteria (Malczewski and Rinner, 2015). 


\title{
A REVIEW OF PRACTITIONER PLANNING SUPPORT TOOLS TO HELP MEASURE, UNDERSTAND, AND REALIZE SUSTAINABILITY, LIVABILITY, AND EQUITY OUTCOMES
}

\begin{abstract}
At the national level, both EPA and DOT have promoted tool development for specific uses in addressing measures of sustainability and livability. Several tools and frameworks have emerged from states and regional agencies, as well as from academic research teams, professional bodies, and international groups. Table 1 summarizes the tools and frameworks that are available to evaluate transportation and land use projects related to at least some aspects of sustainability, livability, and equity.
\end{abstract}

\section{Table 1. Sample of Public Sustainability and Livability Planning Tools}

\section{Tools}

East Tennessee's Regional Plan for Livable Communities Livability Dashboard. A website has been set up as an example of a Livability Dashboard to track scenarios and indicators linked to East Tennessee's Regional Plan for Livable Communities.

Transit Livability Assessment Tool (CUTR University of South Florida for FTA). The project tasks including cataloging potential measures for livability and creating a data collection plan. Other tasks include developing a livability index database, developing livability index scores, and developing a livability index dashboard. A final task is demonstrating the dashboard, measures, and applicability in practice.

A Composite Sustainability Index (Atlanta, GA). Considers multidimensional conflicting criteria in the transportation planning process and identifies the most sustainable (or least unsustainable) plan for predetermined objectives.

Envision (Harvard's Institute for Sustainable Infrastructure). Evaluates, grades, and gives recognition to the community, environmental, and economic benefits of infrastructure projects.

GreenLITES (New York State Department of Transportation). Expanded program includes rating systems, spreadsheets, and other metrics to assess projects, plans, and operations and maintenance programs, as well as regional programs.

Greenroads (Greenroads Foundation; developed by University of Washington researchers and global engineering firm $\mathrm{CH} 2 \mathrm{M}$ Hill). A sustainability rating system for roadway design and construction. It is applicable to all roadway projects including new projects, reconstruction and rehabilitation (including overlays), bridges, or any other project in which a road is involved. Performance metric awards points to more sustainable practices during the design and construction phases of roadway projects

Illinois Livable and Sustainable Transportation (I-LAST) (Illinois Department of Transportation). Checklist of potentially sustainable practices is followed by a description of the intent of each category in the checklist and the rationale and measures of effectiveness for each item. Lists of source materials and additional background resources for each item assist in understanding and applying the practices.

Infrastructure Voluntary Evaluation Sustainability Tool (INVEST) (FHWA). Web-based self-evaluation tool with three categories or criteria: project development, operations and maintenance, and system planning. Assigns each practice a point value (weight) according to its relative impact on roadway sustainability.

Least Cost Planning (Oregon Department of Transportation). Model for use as a decision-making tool in the development of plans and projects at both the state and regional levels. Livability, safety, equity, economic vitality, and environmental stewardship will be evaluated side-by-side with traditional considerations such as capital costs.

Model of Sustainability and Integrated Corridors (MOSAIC) (Maryland State Highway Administration). Tool employs a Microsoft Excel spreadsheet. Six categories of sustainability indicators: mobility, safety, socioeconomic impact, natural resources, energy and emissions, and cost. Includes more than 30 sustainability performance measures.

KeepSpace Project Assessment Tool (State of Rhode Island). Spreadsheet tool assesses: transportation choice and accessibility, housing choice and affordability, economic development, support of existing communities and designated growth centers, community character and collaboration. With optional weighting.

Sustainability Enhancement Tool (Texas Department of Transportation). Excel-based calculator that applies performance measures for sustainability at the highway corridor level; includes 12 performance measures.

Sustainable Transportation Access Rating System (STARS) (Oregon, Washington, California, and Nevada). A framework applies 29 credits organized into six categories: integrated process; access; climate and energy; ecological function; cost-effectiveness analysis; and innovation. 


\section{Tools}

Sustainable Corridor Rating System (University of Delaware, Newark). Methodology for the development of rating systems for urban corridors and mobility-focused transportation systems.

CEEQUAL (Transnational). Online assessment tool scores project performance on management, environmental, and social issues.

Evaluative and Logical Approach to Sustainable Transport Indicator Compilation (ELASTIC) (United Kingdom). Framework for identifying and selecting a small subset of sustainable transport indicators.

Green Guide for Roads (Transportation Association of Canada). Initial framework includes 13 areas where sustainability practices can be applied, with a description of requirements and associated best practices or strategies. Applies to all types of roads in urban and rural settings and includes sustainability considerations such as improved compatibility and livability; universal accessibility; modal equity; conservation of resources; affordability on a full life-cycle basis; and environmental protection.

Urban.Access (Israel). Developed as an ArcGIS extension that can be used in urban regions worldwide where highresolution geographic information system (GIS) data are available. Enables a detailed representation of travel times by transit and car and makes it possible to compare accessibility levels by transport mode.

ATC National Guidelines Systems Planning. Framework for route and link planning developed in Australia by Austroads Inc., 2009; assesses various routes and links in the process of road transportation planning.

Urban Social Vulnerability Index Tool. Developed by Robert Goodspeed, this tool is used to extend methods of social vulnerability analysis developed in the context of natural hazards to urban development.

IWR-APT (Assistance for Planning Teams). An online software program to help planners create, edit, analyze, and manage their study materials. The modules include: Risk Register, Decision Management Plan, Decision Log, Study Issue Checklist, and Smart Planning Deliverable Workflow.

Corps Risk Analysis Gateway. A website maintained by the Institute for Water Resources (IWR) for understanding the Corps model for risk analysis.

Sources: Adapted from CTC \& Associates, TRIS

In addition to publicly developed resources, a number of scenario planning tools were evaluated by the research team, including Envision Tomorrow Plus (ET+), INDEX, iPlaces3, Urban Footprint, and Rapid Fire Models. Given the need for their application to involve interagency collaboration and public involvement, it was important to consider how adaptable and transparent these tools are.

Following the specific needs of the agency or agencies responsible, the underlying goal of the majority of these tools is to support better coordination of transportation and land use planning (Ramini, 2010). Many of these tools have a secondary goal of highlighting trade-offs between the dimensions of sustainability, livability, and equity.

\section{Review of a Sample of Online Mapping Applications and User Interface}

An important aspect of any planning support tool for greater inter-agency and public collaboration is that it have an accessible and easy-to-interpret geospatial (mapping) interface. Accessibility and ease of use is an important aspect of mapping systems and of the Smart Mobility Calculator, where the wide range of anticipated users (planners of all types, members of the public, policy makers) are not guaranteed to have previous GIS or mapping experience. Therefore, the authors conducted a review of useful online indicator tools with mapping interfaces. 


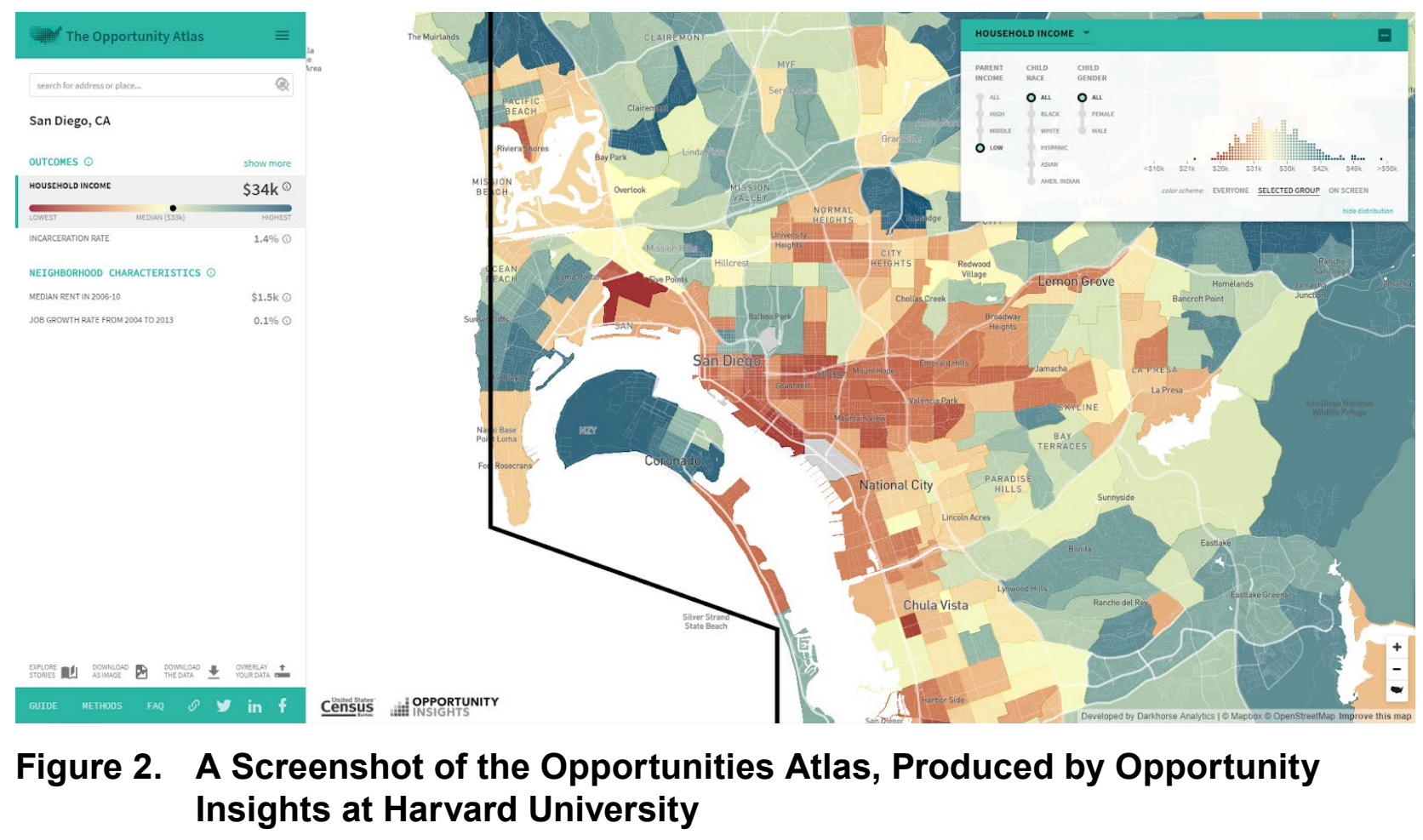

Existing online mapping tools include websites such as the Opportunities Atlas, the California Healthy Places Index, and the Center for Neighborhood Technology (CNT) Housing and Transportation $[\mathrm{H}+\mathrm{T}]$ Affordability Index. The Opportunities Atlas tracks adult outcomes for US census tracts where children grew up. For any given census tract, a variety of metrics can be selected and viewed for adults who spent their childhood (born between 1978 and 1983 ) in that tract. The map shows one metric at a time along a blue-to-red scale, with average and neighborhood characteristics appearing along the left side. The mapping tool is also able to calculate and graph statistics for only the area shown on the screen, rather than nationwide statistics. For more information on other tools, see the Appendix.

\section{SECTION CONCLUSION}

In reviewing these planning support tools, it was revealed that all had limited sensitivity to changing facilities for anything but single-occupancy vehicles and transit. Even the most basic auto alternatives such as pedestrian bicycle facilities were limited to changes in intersection density and measures of mixed-use entropy. Another limitation is that innovative transportation solutions and policies, such as person-sized-motorists (PSM, including e-scooters), neighborhood electric vehicles (NEV), car sharing, and bike sharing, are even less researched. While the authors reviewed the growing body of research on the effects of bicycle facilities on travel behavior, much work needs to be done to better incorporate the effects of these facility investments in planning processes.

Many scenario planning tools rely on research from Ewing and Cervero (2010), and on the work behind other tools, such as the MXD tool developed by Ewing et al. (2013), which relies on such measures as intersection density and a measure of entropy for mixed-land uses, which are really too coarse to truly understand what happens when new facilities are put in 
for bicycling, pedestrians, or emerging services, such as e-scooters and NEVs. Promising research to address these issues can be found in LA Metro's bike modeling project and research currently underway at SDSU's Active Transportation Research Center. This review helped inform the design of the interface of the Smart Mobility Calculator, especially in terms of the placement, design, and dynamic readout of the dashboard.

Building on the above. the next section presents a discussion of the use of the Livability and Smart Mobility Calculators, and how specifics on measures, frameworks and decision processes discussed up to this point will benefit the future of sustainability, livability, and equity for all Californians. 


\title{
IV. LIVABILITY AND SMART MOBILITY CALCULATORS
}

\author{
New Tools for Measuring Understanding and Realizing Smart Growth for \\ Sustainability, Livability, and Equity
}

\section{INTRODUCTION AND BACKGROUND}

This section provides a brief "walk through" of the development of a specific set of frameworks and tools by the research team designed to (a) help agencies evaluate the strengths and weaknesses of transportation land use coordination (TLC) and smart growth, and then (b) help determine the best policies going forward to realize a stronger transportation land use coordination and smart growth.

Transportation and Land Use Coordination (TLC) is a widely recognized approach for achieving what is often referred to as "smart growth." However, absent substantial institutional changes enabling transportation, land use, and other disciplines to truly work in a coordinated fashion, we are left to use data, performance measures, methods, and policy guidance frameworks to realize TLC.

In response, this section discusses the development of two planning support tools (PSTs) and their underlying frameworks and measures to help an array of stakeholders better understand the sustainability, livability, and equity performance of urban places so they can make more informed decisions about how communities and regions should grow and evolve, now and in the future.

\section{The Livability and Smart Mobility Calculators}

The Livability Calculator for the Handbook for Building Livable Transit Corridors (http://bit.ly/ LTCHanbook) builds on the foundations of the Six "Livability Principles" of the 2009 HUD, US DOT, and EPA Sustainable Communities Partnership by operationalizing them through a focused set of transportation, land use, and quality of life metrics. As these are essentially re-statements of EPA's ten smart growth principles, this is an effective planning support tool for measuring urban quality, since it relates to such concepts as smart growth and new urbanism, as well as the associated sustainability, livability, and equity outcomes.

The Livability Calculator assesses smart growth and livability performance by operationalizing the six HUD/EPA/US-DOT principles, as shown in the radar graphic in Figure 3 below. The operationalized principles are as follows:

1. High-quality transit, walking, \& bicycling opportunities,

2. Healthy, safe \& walkable transit corridor neighborhoods,

3. Vibrant \& accessible community, cultural \& recreational opportunities,

4. Accessible social \& government services, 
5. Transit-accessible economic opportunities, and

6. Mixed income housing near transit (this currently supports the social equity principle, which measures housing affordability and income diversity).

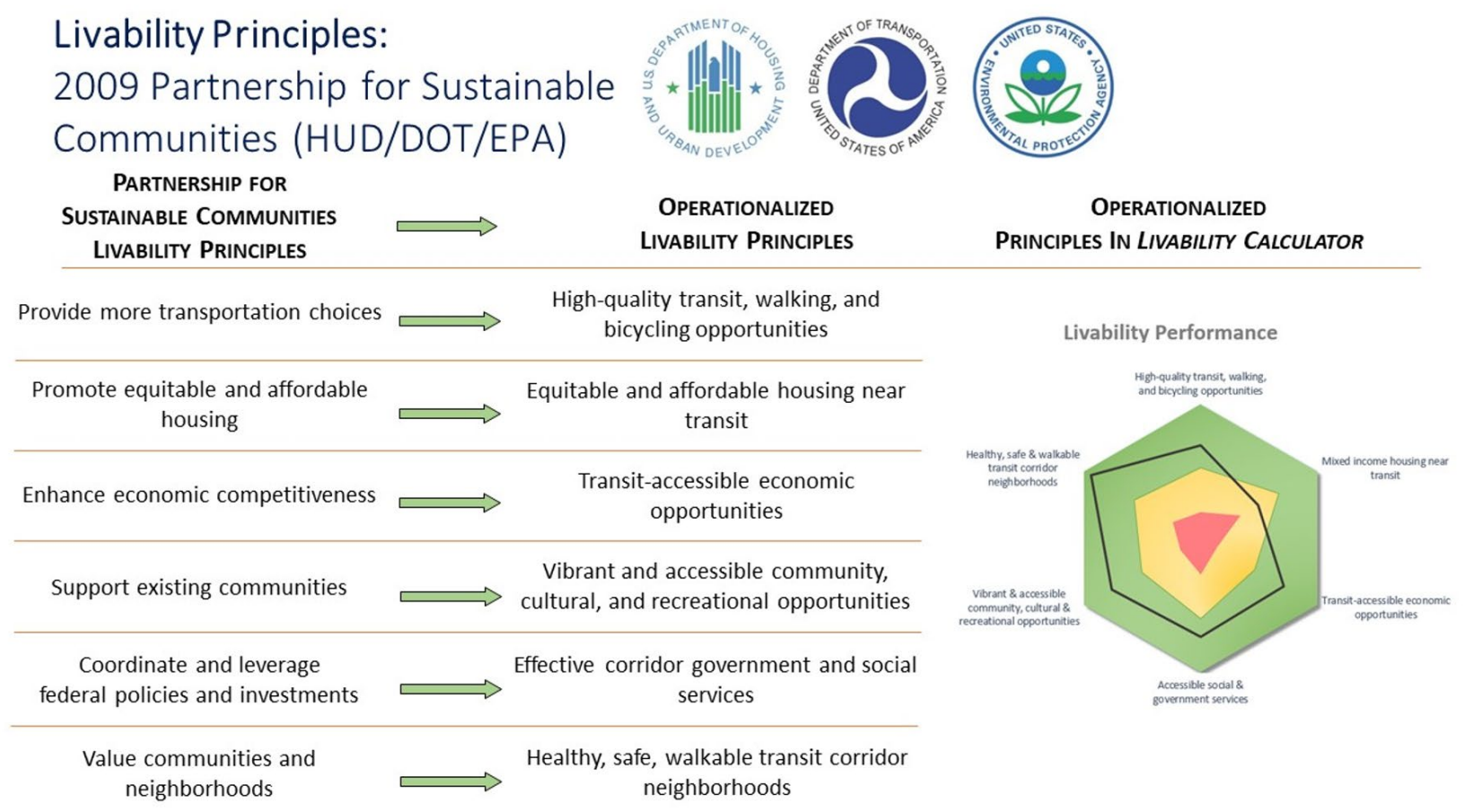

Figure 3. Operationalizing the 2009 Livability Principles of the HUD/US-DOT/EPA Sustainable Communities Partnership

\section{Livability as Access to Opportunities to Improve/Maintain One's Desired Quality of Life}

As discussed earlier in the section on Livability Ethics, smart growth/livability performance is suggested by the authors to be framed by measuring people's equitable access to livability opportunities to improve and maintain one's desired quality of life. Such frameworks help guide the use of measures that then provide guidance on policy decisions. Therefore, the Livability Calculator currently assesses urban quality by operationalizing the Six HUD/EPA/ USDOT principles, as shown in Figure 3 above. From left to right the original Livability Principles are listed, followed by the operationalized Livability Calculator Principles, and then an example of a radar graphic readout from the Livability Calculator itself which lists the operationalized principles as well.

The above framework and principles can be built upon to determine what to measure and how these measures guide policy. In the development of the Handbook and Calculator, the authors gathered an extensive array of geo-spatial data to explore the relationships between the measures of urban quality and a host of quality-of-life outcome measures (see Table 2 below). For this study, a California statewide database of built environment characteristics and sustainability performance metrics was created for 8,043 census tracts and 23,212 census block groups. 


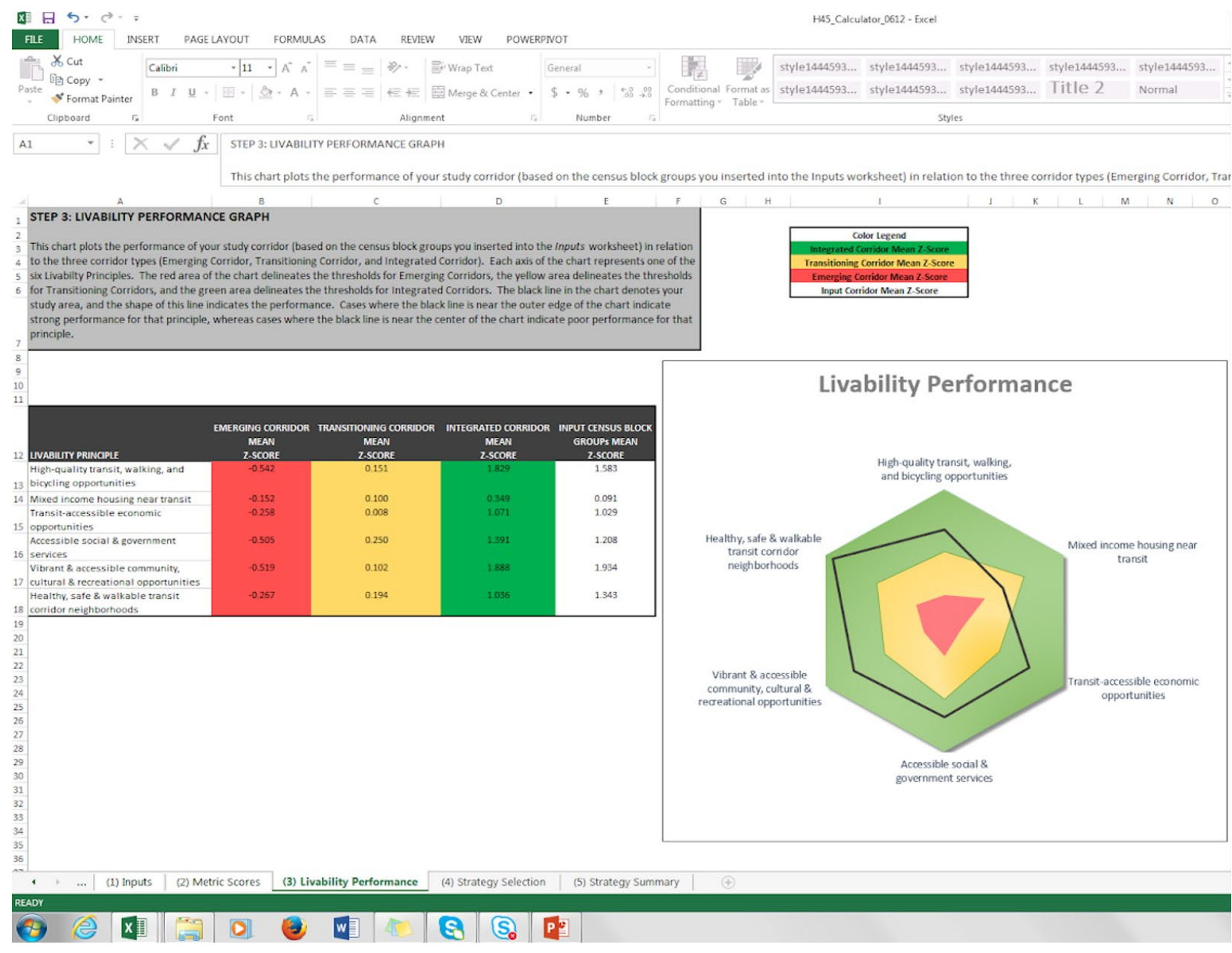

Figure 4. Livability Calculator for the Handbook for Building Livable Transit Corridors

Source: to download both the Livability Calculator and the Handbook for Building Livable Transit Corridors http://bit.ly/ LTCHanbook

Table 2 shows the twelve metrics in the Livability Calculator of the operationalized Livability Principles of the 2009 HUD/US-DOT/EPA Sustainable Communities Partnership.

\section{Table 2. The Twelve Metrics of the Livability Calculator: Operationalizing the Livability Principles of the HUD/USDOT/EPA Sustainable Communities Partnership}

\begin{tabular}{|c|c|c|}
\hline $\begin{array}{c}\text { Transit Corridor Livability } \\
\text { Principles }\end{array}$ & Metric & Data Source(s) \\
\hline \multirow{2}{*}{$\begin{array}{l}\text { High-quality transit, walking, } \\
\text { and bicycling opportunities }\end{array}$} & Transit jobs accessibility & $\begin{array}{l}\text { EPA's Smart Locations Database (SLD) } 2013 \\
\text { D5br: Jobs within 45-minute transit commute, } \\
\text { distance decay (walk network travel time) } \\
\text { weighted }\end{array}$ \\
\hline & $\begin{array}{l}\text { Transit service coverage } \\
\text { (aggregate frequency of transit } \\
\text { service per sq. mile) }\end{array}$ & $\begin{array}{l}\text { SLD } \\
\text { D4c: Aggregate frequency of transit service within } \\
0.25 \text { mile of block group boundary per hour during } \\
\text { evening peak period }\end{array}$ \\
\hline
\end{tabular}


Mixed-income housing near transit
Housing unaffordability (percent of income spent for housing)
HUD's 2012 Housing Affordability Index Data Set (HAl)

hh_type1_: housing cost as a percent of income for the regional typical household, defined as mean $\mathrm{HH}$ size for region, median income for region, average number of commuters per $\mathrm{HH}$ for region

Income diversity (variance from regional median household income)

National Historical Geographic Information System (NHGIS), 2010

Census ID B19013: Coefficient of variance of block group median household income compared to either the metro area or the state median; closer to zero means less diversity, closer to one means more

Jobs density (employees/acre) SLD

D1c: Gross employment density employees (jobs)/acre on unprotected land, 2013

Transit-accessible economic opportunities

Accessible social \& government services

Vibrant \& accessible community, cultural \& recreational opportunities

Healthy, safe, \& walkable transit corridor neighborhoods

\begin{tabular}{ll}
\hline $\begin{array}{l}\text { Retail jobs density (retail } \\
\text { employees/acre) }\end{array}$ & $\begin{array}{l}\text { SLD } \\
\text { D1c_Ret10: Gross retail employment density } \\
\text { employees (jobs)/acre on unprotected land }\end{array}$ \\
\hline Transit ridership balance of flows & $\begin{array}{l}\text { Transit agency route/line data } \\
\text { Inbound (to CBD) daily boardings/inbound daily } \\
\text { alightings }\end{array}$ \\
\hline Health care opportunities (health & SLD \\
care employees/acre) & D1c8_Hlth10: Gross health care (8-tier) \\
& employment density employees (jobs)/acre on \\
& unprotected land \\
\hline Population density (population/ & SLD \\
acre) & D1b: Gross population density (people/acre) on \\
& unprotected land \\
\hline Access to culture \& arts & SLD \\
(\# corridor entertainment & D1c_Ent10: Gross entertainment employment \\
employees/acre) & density employees (jobs)/acre on unprotected \\
& land \\
\hline Pedestrian environment & SLD \\
(intersection density) & D3bmm4: Intersection density in terms of \\
& multimodal intersections having four or more legs \\
& per square mile \\
\hline Pedestrian collisions per 100,000 & Transportation Injury Mapping System (TIMS) \\
pedestrians & 2010 \\
& Pedestrian collisions per 100,000 pedestrians \\
\hline &
\end{tabular}

\section{SMART MOBILITY CALCULATOR: OVERVIEW}

\section{(https://smartmobilitycalculator.netlify.app/)}

Building on the earlier work on the Livability Calculator, described above, Dr. Appleyard and his student research team developed an online Smart Mobility (SM) Calculator (https:// smartmobilitycalculator.netlify.app/) using similar data and metrics as was gathered for the development of the Livability Calculator. (For more information, see the website https:// transweb.sjsu.edu/research/1899-Smart-Growth-Equity-Framework-Tool.) One of the goals was to make the visualization of these data and calculations more accessible for key stakeholders (practitioners, members of the public, and politicians) to use toward analysis 
and policy guidance for a number of different transportation and land use coordination issues, including climate action planning, corridor planning, and new housing initiatives (such as SB 50 and SB 827). The SMC can also be used for new environmental regulations under SB 743, which allows for streamlining of significant developments in areas that are $15 \%$ below regional averages for per-capita vehicle miles travelled (VMT) as opposed to level of service (LOS). The SM Calculator can even be used to determine the performance of future transportation scenarios, including but not limited to those future scenarios related to autonomous vehicles (AVs) and Mobility as a Service (MaaS).

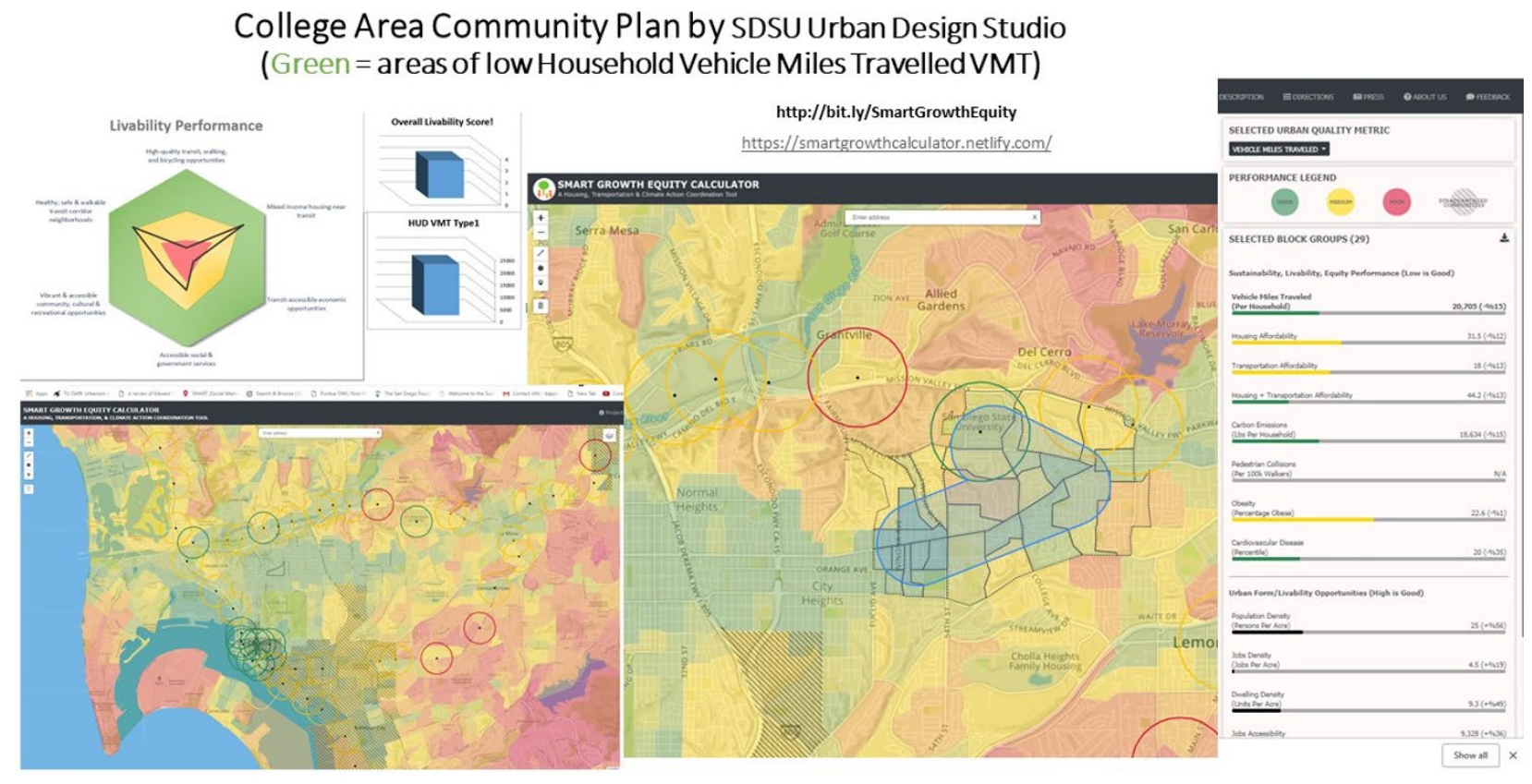

Figure 5. An Example of How the Performance Radar Graphic from the Livability Calculator Can be Merged with the Smart Mobility Calculator

Upon hovering the mouse cursor over an area, one can see percentages of VMT per capita displayed on dashboard on the right, showing how much an area is above or below the regional average. Along these lines, the SM Calculator can also be used for new housing initiatives. For example, it can show the areas around transit that could potentially be upzoned (per bills like SB 50); the SM Calculator shows the areas that are in close proximity to transit, while also showing the location of disadvantaged communities (per SB 535) in the hatched areas. The disadvantaged communities overlay is key to being able to inform people of the need to enact planning processes with the members of the community where they can determine how they want to manage potential forces of gentrification and where they can choose to enact such measures as anti-displacement policies and practices.

\section{The Data of the Smart Mobility Calculator}

The data and sources that show up on the calculator's dashboard on the right side of the screen are shown in Table 3.

As shown in Table 3, the SM calculator provides two types of data: the first are urban 
quality outcome metrics that gauge the sustainability, livability, and equity performance of an area. For these measures lower values are better, such as lower VMT, lower carbon emissions, housing costs, etc. Second are urban form livability opportunity measures. These are measures of the built environment that provide people the ability to access livability opportunities-such as ability to access jobs via walking and transit.

Table 3. The Metrics of the Smart Mobility Calculator

\begin{tabular}{|c|c|}
\hline Metric & Data Source(s) \\
\hline \multicolumn{2}{|c|}{ Sustainability, Livability, Equity Performance } \\
\hline \multicolumn{2}{|c|}{ Lower Values are Better } \\
\hline Vehicle Miles Traveled per Capita & $\begin{array}{l}\text { Caltrans' California State Travel Demand Model (CSTDM) } 2016 \text { us- } \\
\text { ing } 2012 \text { California Household Travel Survey }\end{array}$ \\
\hline Vehicle Miles Traveled per Household & $\begin{array}{l}\text { From HUD's } 2012 \text { Housing Affordability Index Data Set (HAI) - hh } \\
\text { type1_vmt- Vehicle Miles Traveled per Household (the authors are } \\
\text { working to get updated VMT per capita data from Caltrans) }\end{array}$ \\
\hline Housing Affordability & $\begin{array}{l}\text { HUD's } 2012 \text { Housing Affordability Index Data Set (HAI) (the authors } \\
\text { use this measure as it is aggregated to Census Block Group level) } \\
\text { hh_type1_: housing cost as a percent of income for the regional typ- } \\
\text { ical household, defined as Avg HH size for region, median income } \\
\text { for region, average number of commuters per HH for region }\end{array}$ \\
\hline Transportation Affordability & From HUD’s 2012 Housing Affordability Index Data - hh_type1_t \\
\hline $\begin{array}{l}\text { Pedestrian Collisions per 100,000 } \\
\text { Pedestrians }\end{array}$ & $\begin{array}{l}\text { Transportation Injury Mapping System (TIMS) } 2010 \\
\text { Pedestrian collisions per 100,000 pedestrians }\end{array}$ \\
\hline WalkScore & Frontseat \\
\hline Cardiovascular Disease & $\begin{array}{l}\text { Centers for Disease Control: } 500 \text { Cities Data } \\
\text { Cardiova_1 }\end{array}$ \\
\hline Obesity & $\begin{array}{l}\text { Centers for Disease Control: } 500 \text { Cities Data } \\
\text { OBESITY_Cr }\end{array}$ \\
\hline
\end{tabular}

\section{Urban Form/Livability Opportunities}

Higher Values are Better

\begin{tabular}{ll}
\hline Transit Jobs Accessibility & EPA's Smart Locations Data Set (SLD) 2013 \\
& D5br: Jobs within 45-minute transit commute, distance decay (walk \\
& network travel time) weighted \\
& SLD \\
Population Density (population/acre) & D1b: Gross population density (people/acre) on unprotected land \\
& SLD \\
Jobs Density (employees/acre) & D1c: Gross employment density employees (jobs)/acre on unpro- \\
& tected land, 2013 \\
Pedestrian Environment (intersection density) & SLD \\
& D3bmm4: Intersection density in terms of multimodal intersections \\
& having four or more legs per square mile \\
\hline &
\end{tabular}

\section{VMT and a Place Typology}

Why is VMT per capita the first layer that shows up when you open the SM Calculator? VMT per capita is used as this is one of the most important measures for key issues we are trying to address, such as housing, climate action planning, and the new environmental 
regulations replacing level of service (LOS) with VMT (per SB 743). In addition to VMT, the SM Calculator also provides a place typology based on Caltrans' own Smart Mobility Framework, also using the Location Efficient Neighborhood Design (LEND) Index, as shown below.

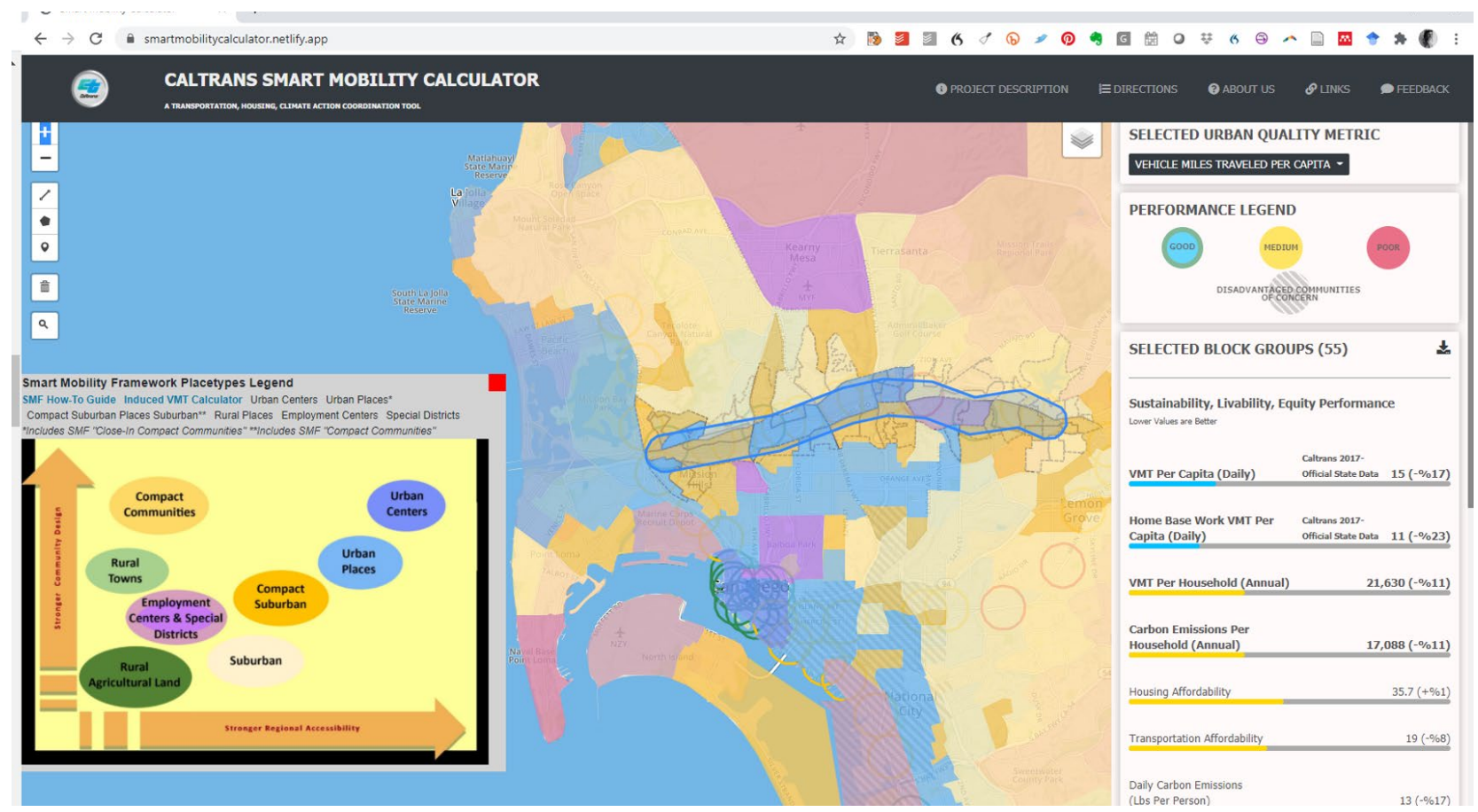

Figure 6. The Location Efficient Neighborhood Design (LEND) Smart Mobility Framework Place Typology in the Smart Mobility Calculator 


\section{Average VMT Per Capita-San Diego}

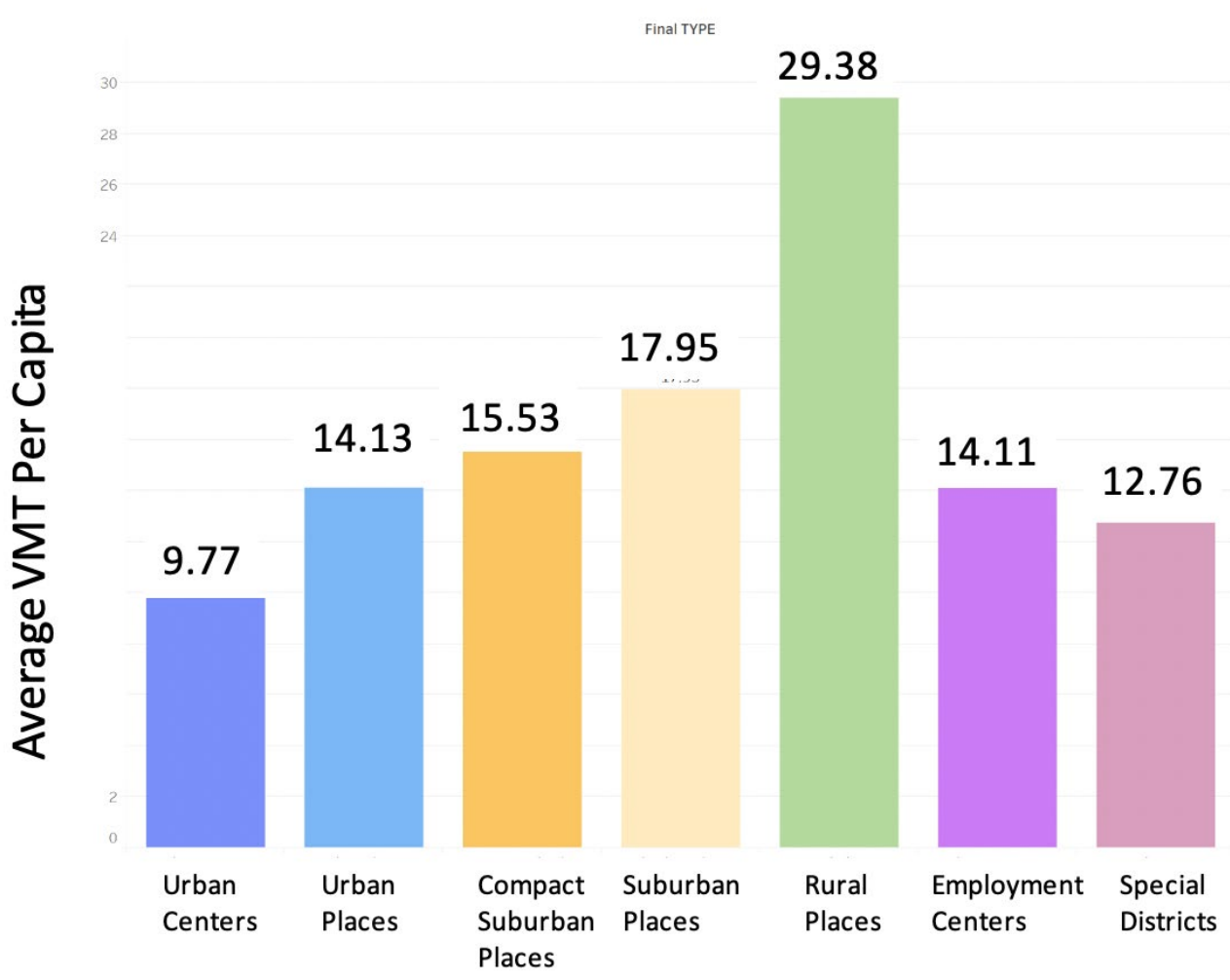

Figure 7. Average VMT per Capita Using the Location Efficient Neighborhood Design (LEND) Index and Caltrans' SMF Place Typology in San Diego

\section{Using VMT: The Transportation Land Use Connection}

The connection between lower vehicle miles traveled (VMT) and urban (versus suburban) places, illustrated above, shows how achieving a better balance between housing and jobs can lead to more sustainable outcomes. As shown in Figure 7 above, by doing such things as encouraging infill development and curbing urban sprawl, a coordinated transportation and land use planning approach can improve a regional transportation plan by lowering overall trip distances and automobile travel in support of transit, walking, and bicycling. Such VMT reductions can be realized through both regionally minded land use planning and pricing policies, which should be supported at all levels of government.

\section{THE USES OF THE SMART MOBILITY CALCULATOR}

In brief, the Smart Mobility Calculator can be used in the following ways:

- Caltrans' New Corridor Planning Process: The SM Calculator can help with all aspects of Caltrans Corridor Planning Process, especially in the initial stages (see next section).

- CEQA project development review analysis under SB 743: The SM Calculator can 
help with project development review analysis under the new regulations of SB 743 which allows for environmental streamlining of significant developments in areas that are $15 \%$ below regional averages for VMT.

- Climate action planning: The SM Calculator shows how many pounds of carbon per household will be generated from travel in different locations in the region, which can help with dialogues around climate action planning.

- New housing initiatives: This tool can help ensure new housing initiatives are equitable: first, it shows the areas that are in close proximity to transit, while also showing the location of disadvantaged communities, per SB 535, which is key to then being able to inform people to enact anti-displacement policies and practices.

- Better transportation and land use coordination between regional transportation planning agencies and local land use authorities, by providing key transportation and land use information at both regional and local scales.

- Helps inform NIMBY conversations by giving people access to key data, such as VMT and pounds of carbon per household in order for all parties to better understand why development should occur in transit/bike/walk accessible areas; by giving people a regional perspective and helping them see how everything is connected and needs to be coordinated through both land use and transportation, everyone can get on the same page and have a more constructive dialogue.

- Performance evaluation of future scenarios related to Autonomous Vehicles (AVs) and Mobility as a Service (MaaS).

- The SM Calculator also provides an atlas of all train stations in California, rating them according to their performance as described in the smart growth \& transportation/ land use coordination (TLC) performance typology outlined in the paper "Are All Stations Equal and Equitable?" (Appleyard et al. 2019). 


\section{ILLUSTRATIVE EXAMPLES OF THE SMART MOBILITY CALCULATOR IN ACTION}

\section{CALTRANS' NEW CORRIDOR PLANNING PROCESS}

Both the Livability and Smart Mobility Calculators can be used for Caltrans' new corridor planning process. They can be used in all phases, especially in the beginning. This section provides an illustrative example of how to use both the SM Calculator and the Livability Calculator toward Caltrans' Corridor Planning Process. For instance, the Smart Mobility Calculator provides the SMF place typology which can provide important insight into the context of a corridor for the baseline performance assessment (see Figure 8).

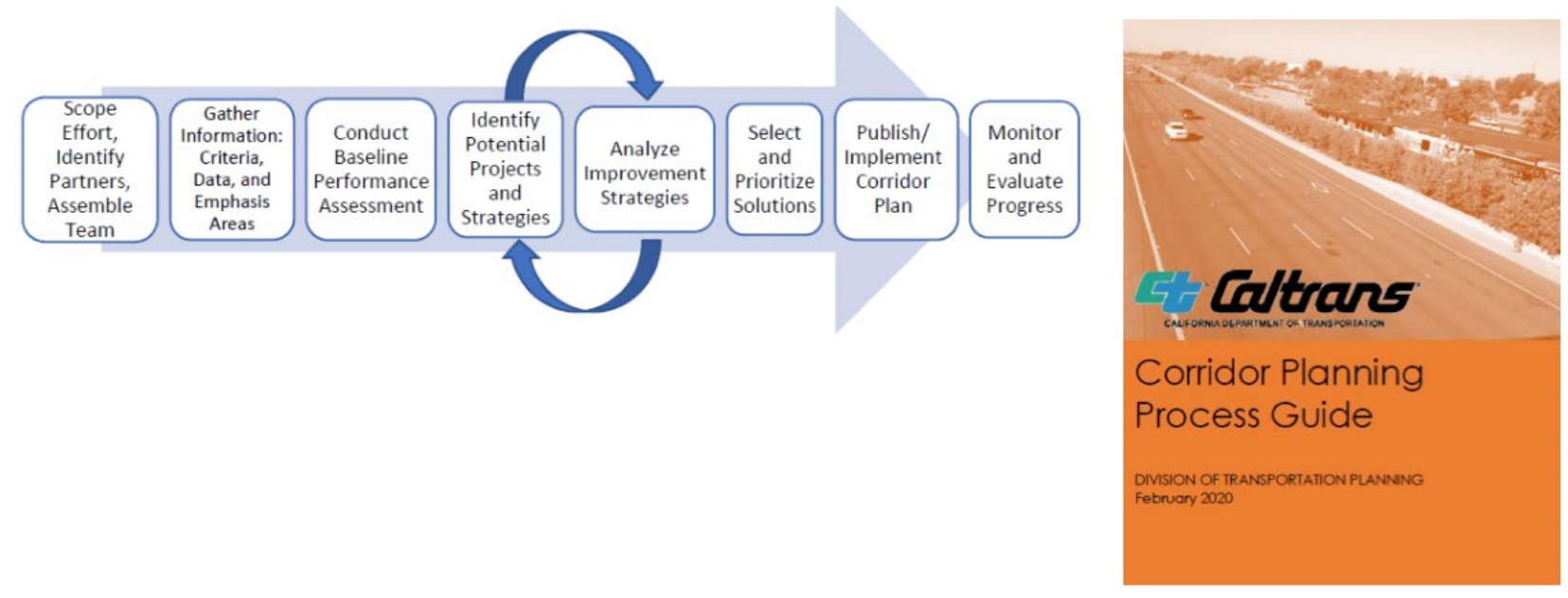

Figure 8. The Caltrans Corridor Planning Process

The Smart Mobility Calculator can also be used to assess the SMF place types for a corridor, which is especially important in the initial phases of the corridor planning process. 


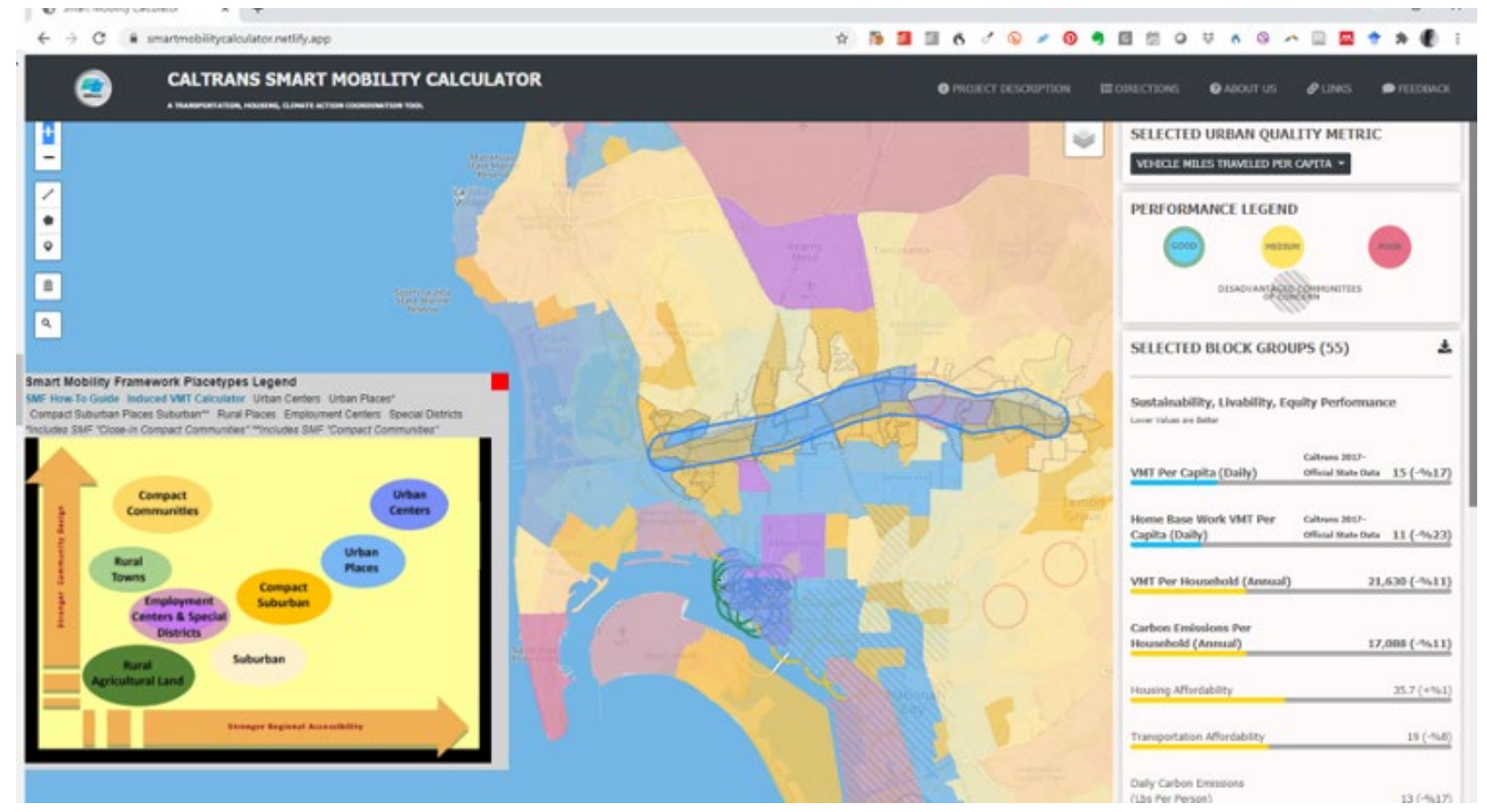

Figure 9. The SMF Place Types Can Also be Displayed in the Smart Mobility Calculator and Used in the Caltrans Corridor Planning Process

The calculators can also be used to develop the required Sustainability Profile which should focus on "reporting corridor performance related to policies that practice environmental stewardship and the fostering of livable, healthy, and equitable communities" (Caltrans Corridor Planning Process 2020). Examples of such measures provided in both Calculators include:

- Criteria pollutants and GHG emission estimates

- VMT per capita in areas served by the corridor

- Measures of multimodal accessibility and connectivity for households and employers

Below is a step-by-step illustrative guide to using the calculators for the corridor planning process, using the I-8 corridor as a case study.

1. Select your corridor of interest in the Smart Mobility Calculator.

2. Download the data from the Smart Mobility Calculator.

3. Select the FIPS codes and input into the Livability Calculator's Input Sheet. 

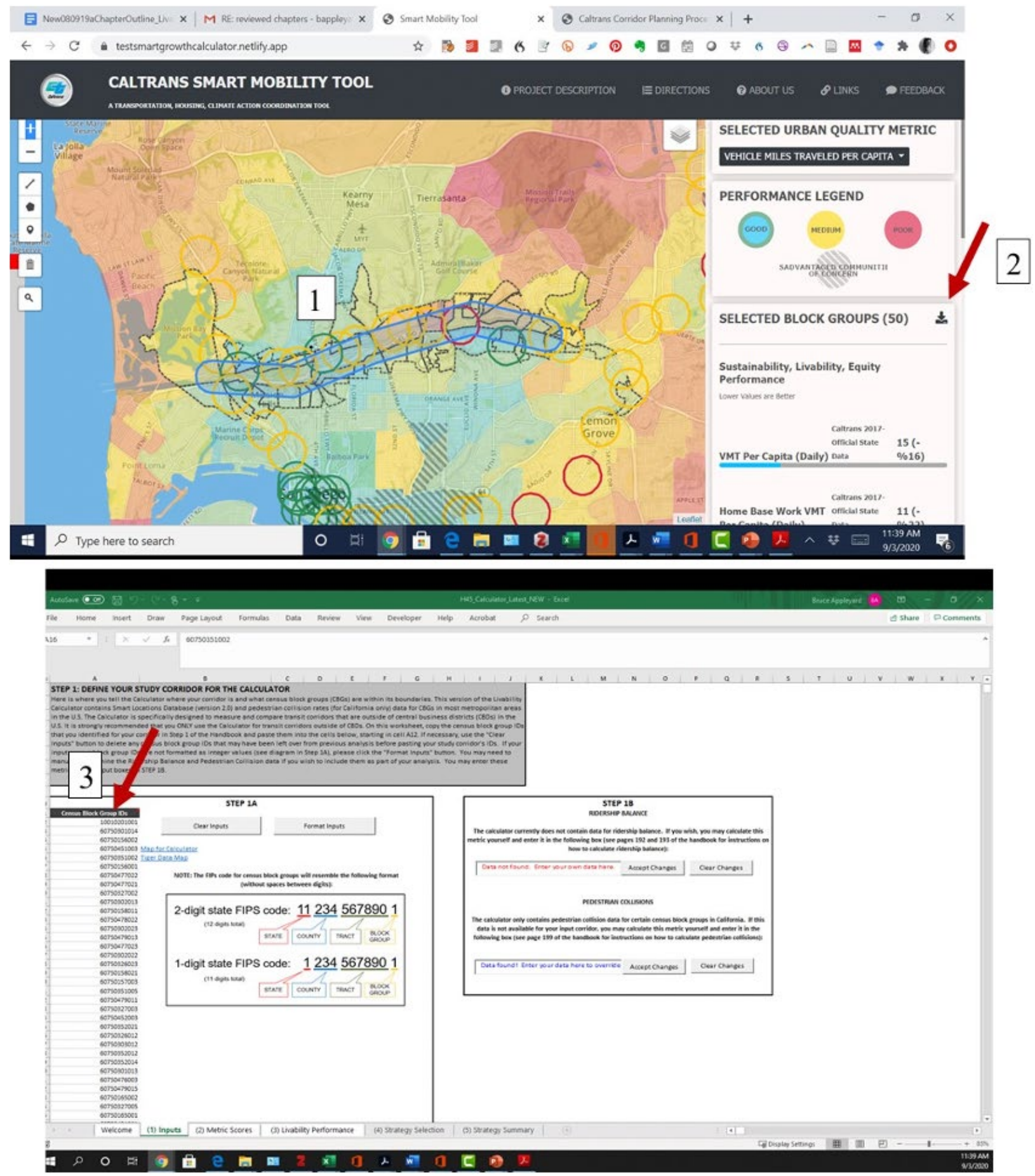

Figure 10. Selecting a Corridor in the Smart Mobility Calculator, then Inputting the FIPS Code Data into the Livability Calculator's Input Sheet

4. View your corridor's livability performance on the Livability Performance Sheet of the Livability Calculator. 


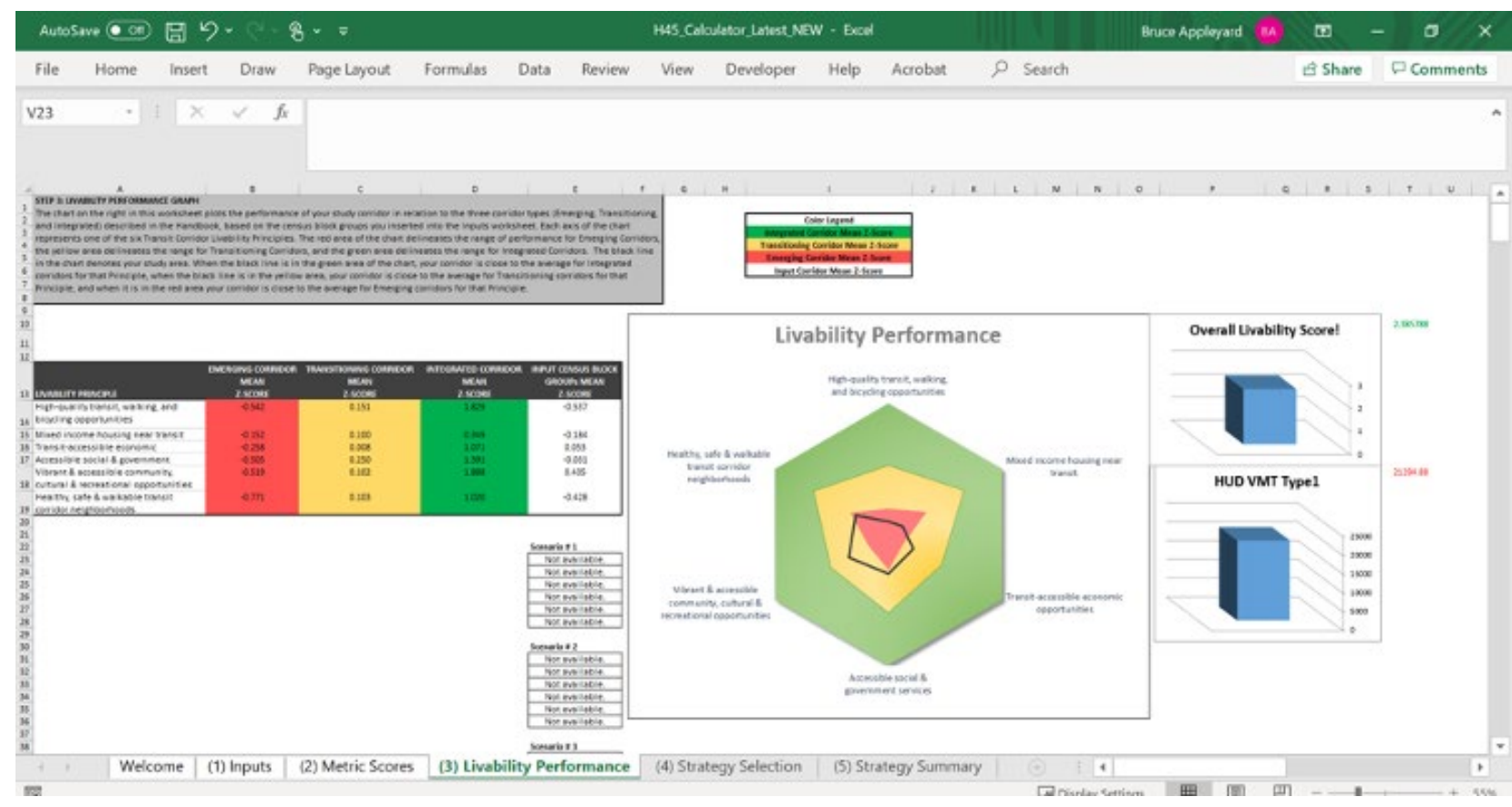

Figure 11. Corridor Performance Displayed in the Livability Performance Sheet on the Livability Calculator

5. Select policies from the Strategy Selection and Strategy Summary Sheet. (Make sure you have a copy of the Handbook for Building Livable Transit Corridors in the same folder as the Livability Calculator).

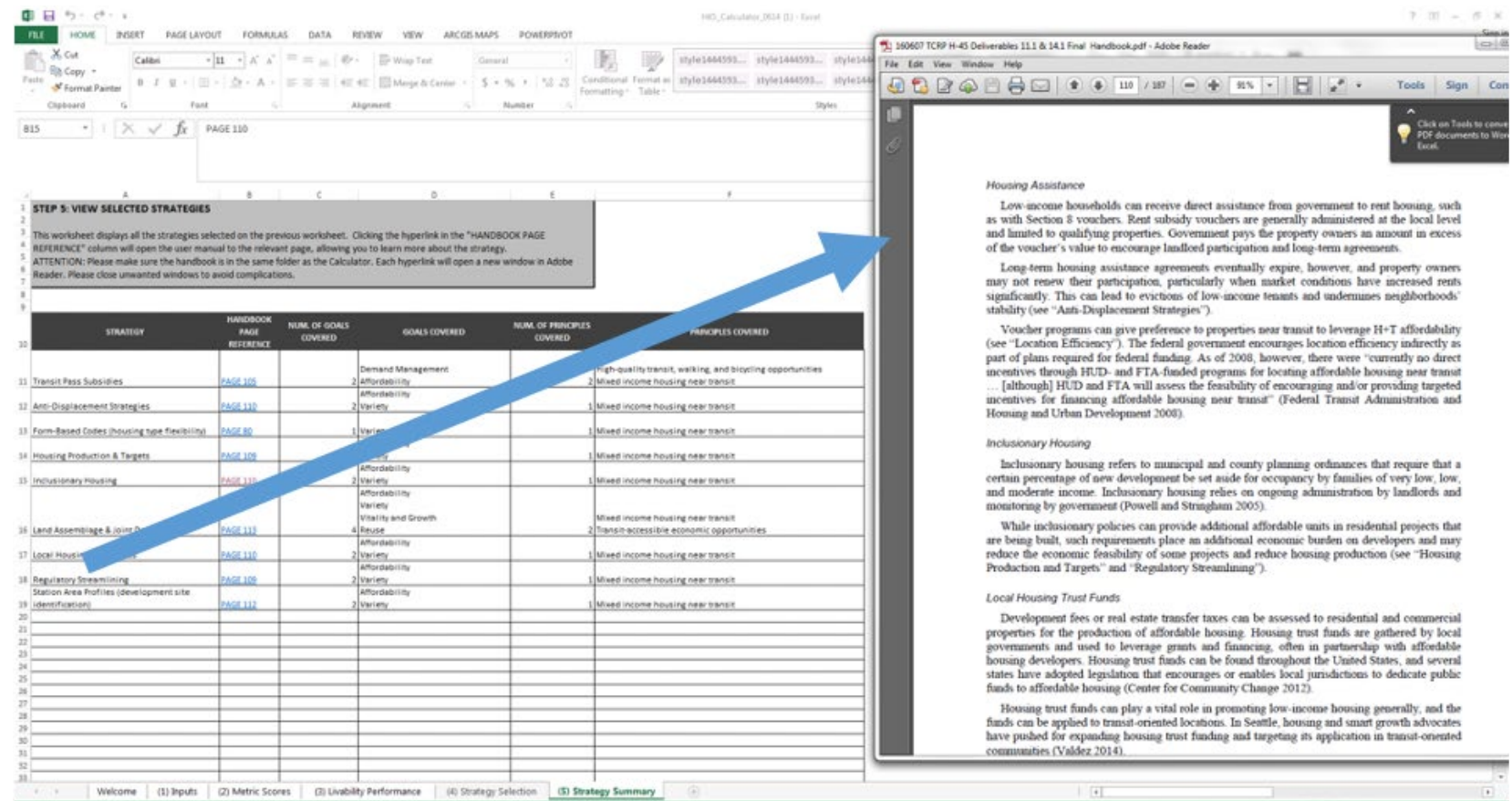

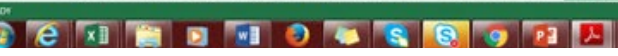

Figure 12. Displaying Policy Options in the Handbook for Building Livable Transit Corridors via the Livability Calculator's Strategy Summary Sheet 


\section{NEW ENVIRONMENTAL REGULATIONS FOR PROJECT DEVELOPMENT REVIEW: USING THE SMART MOBILITY CALCULATOR FOR VMT INSTEAD OF LEVEL OF SERVICE - AN ILLUSTRATIVE EXAMPLE}

Senate Bill 743-which allows for environmental streamlining of significant developments in areas that are $15 \%$ below regional averages for Vehicle Miles Travelled (VMT) - could be a significant game changer in California's ability to achieve a more sustainable, livable, and equitable future.

Why should VMT be below $15 \%$ of regional averages? According to the California Office of Planning Research, $15 \%$ below is chosen as the benchmark for the following reasons:

- Caltrans Strategic Plan: Reduce VMT/cap $15 \%$ by 2020

- SB 375 targets $\approx 15 \%$ collectively statewide

- $A B 32$ scoping plan recommends local governments set GHG

- Reduction targets at $15 \%$ below existing by 2020

- Research shows 15\% VMT mitigation is generally achievable (See CAPCOA's Quantifying Greenhouse Gas Mitigation Measures)

\section{HOW USING VMT INSTEAD OF LEVEL OF SERVICE HELPS TRANSFORM OUR AUTO-MOBILITY PARADIGM}

The pictures in Figure 13 illustrate a critical problem with using level of service (LOS) for evaluating new developments, especially if the goal is to achieve more sustainable, livable, and equitable outcomes. The top image shows an open road that has no congestion. Under the old level of service paradigm dictated by CEQA , this would receive the highest grade, $A$, while the congested road at the bottom would receive a lower grade, possibly an $F$. The problem is that this type of street is more likely located in a suburban or ex-urban area with a low density - and perhaps more importantly, lower levels of regional centrality and access to jobs. Using the SM Calculator, it can be seen that such an area could have relatively high levels of annual vehicle miles traveled per household-somewhere in the range of 25-28,000 VMT per household per year. On the other hand, a more regionally central area, as shown in the bottom photo could be more congested (receiving an LOS grade of $F$ ) but be located in an area that generates much lower VMT per household, somewhere in the range of 15,000 to 18,000 VMT per year. 


\section{Housing \& Transportation Game Changer}

\section{California's SB 743: New Measures for Development Review \& CEQA Streamlining} Use Vehicle Miles Traveled (VMT) instead of congestion-Level of Service (LOS)

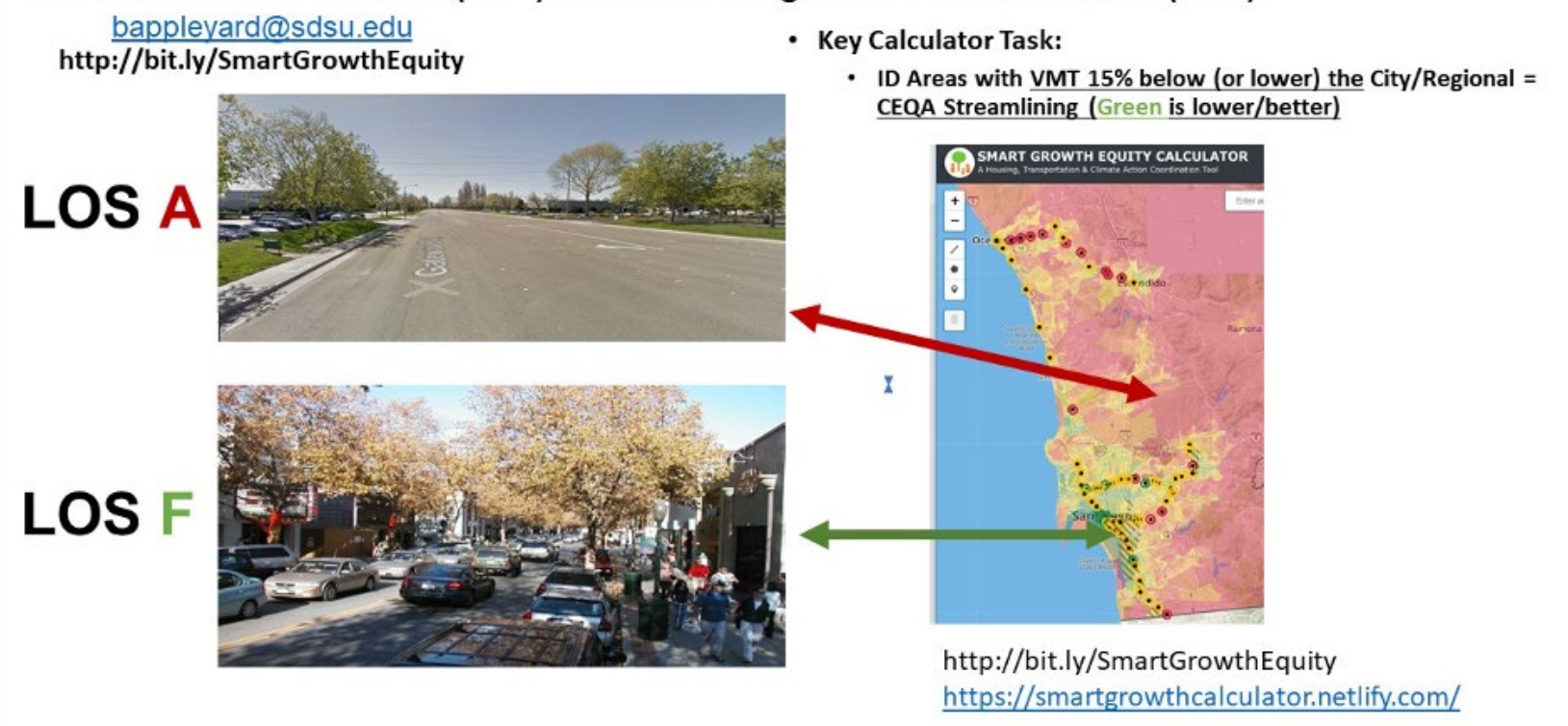

Figure 13. SB 743 Visualization and Examples in Smart Mobility Calculator

\section{HOW THE SMART MOBILITY CALCULATOR CAN HELP WITH VMT ANALYSIS FOR THE CALIFORNIA ENVIRONMENTAL QUALITY ACT (CEQA)}

The SMC can help in California Environmental Quality Act (CEQA) analysis by enabling measurement of the VMT per capita for one's area of interest in relation to agreed-upon regional average. In the example in Figure 14 below, the selected area-which is the El Cajon Boulevard corridor just to the south and west of San Diego State University-is compared with the average VMT per capita for the entire county of San Diego.

Remember, to select an area use the corner selection tool on the left-hand side of the screen. (If selecting another area be sure to deselect the initial area by selecting the trash can icon at the bottom of the toolbox to clear the selection.)

The SM Calculator then calculates a collective average for the urban quality metrics across the selected area and compares it to the regional average. In the example below, the area of interest is cumulatively at about $27 \%$ below the regional average, meaning it qualifies for environmental review streamlining under CEQA as per SB 743.

While more specific analysis is likely needed, this geographical area shows promise for achieving the target of $27 \%$ below the regional average. Under the new California Environmental Quality Act guidelines, per the new SB 743 regulations, this means that significant projects in this area may qualify for development review streamlining. Conversely, these averages can reveal certain areas that are well above the regional average for VMT and should no longer receive the benefits that these areas used to receive under the old level of service (LOS) paradigm (which favored areas that were low density, regionally inaccessible, and consequently more auto-dependent). 


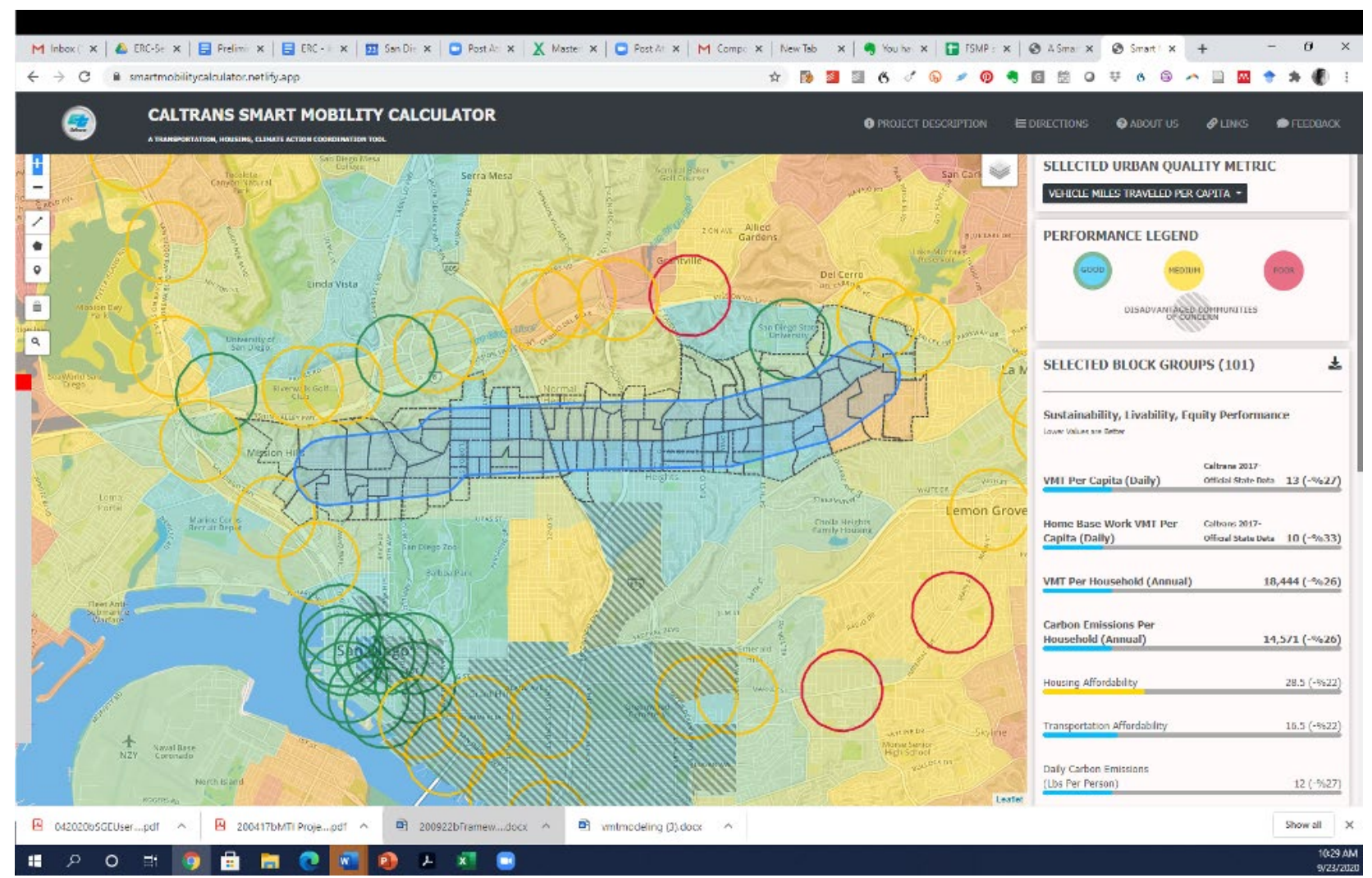

Figure 14. Smart Mobility Calculator Used to Determine SB 743 Compliance 


\section{TOD ATLAS: THE EQUITY OF URBAN QUALITY AROUND TRAIN STATIONS}

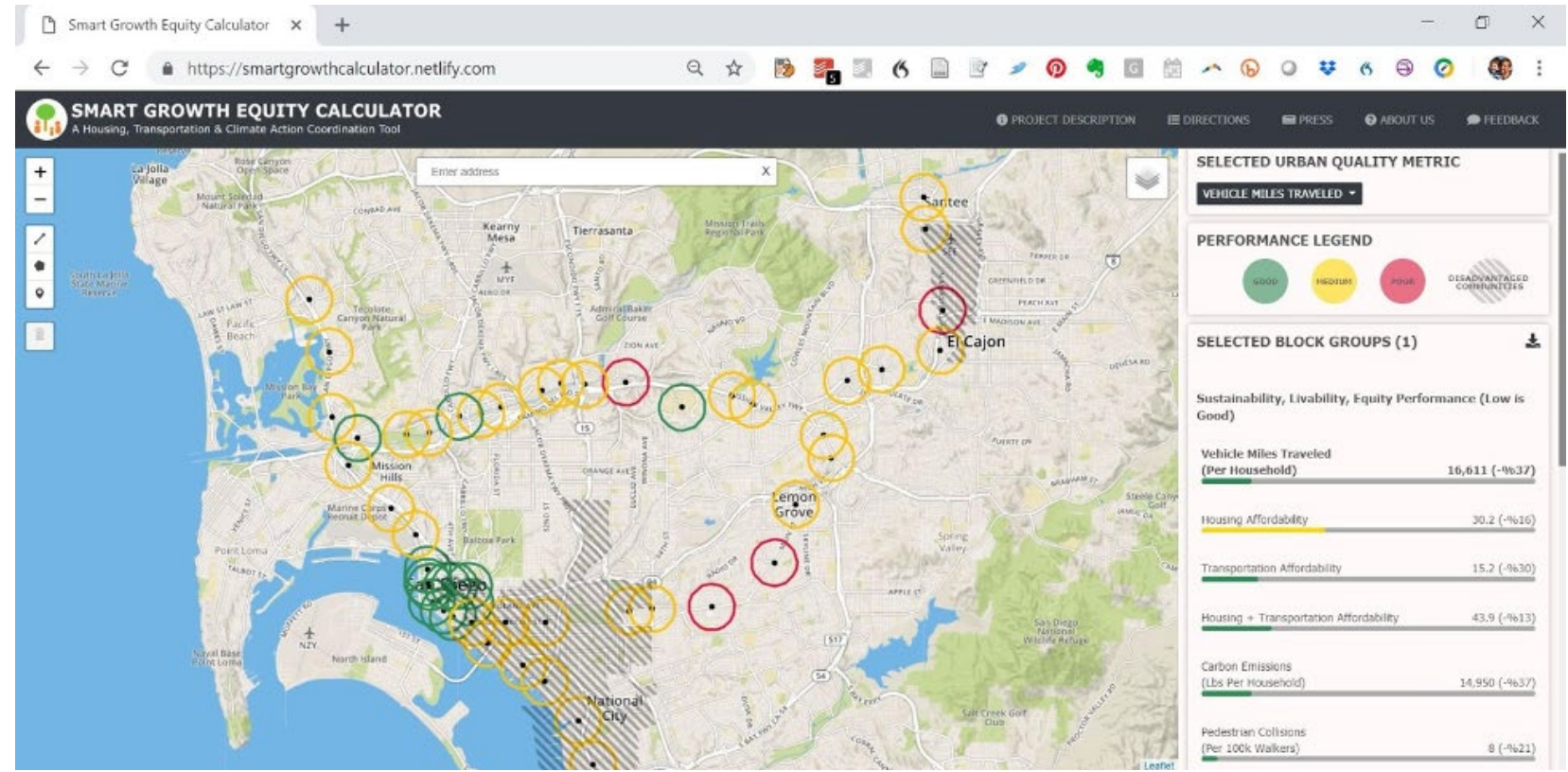

Figure 15. Light Rail Station Performance and 1/2-mile Overlay in the Smart Growth Calculator

Station color key: Red = Emerging; Yellow = Transitioning; Green = Coordinating/Integrating

In the Smart Mobility Calculator, all the light rail stations are color coded according to their performance as described in the smart growth and transportation/land use coordination (TLC) performance typology outlined in the paper "Are All Stations Equal and Equitable?" (Appleyard et al. 2019). Red = Emerging; Yellow = Transitioning; Green $=$ Coordinating/Integrating. The indicators on the right show the performance of a sample coordinating station, which has lower regional averages for household vehicle miles traveled, carbon emissions, and transportation expenditures, but lacking in terms of being affordable because of paradoxically higher housing costs. The hatched areas on the map locate California-designated disadvantaged communities deserving protection from forces of displacement via targeted policies. For more information, see https:// smartmobilitycalculator.netlify.app/ (Appleyard et al., 2018). 


\section{CALTRANS' SMART MOBILITY FRAMEWORK IMPLEMENTATION PROJECT CASE STUDY}

Understanding the performance of urban places in relation to levels of transportation and land use coordination is key to determining the best policy pathways forward for transportation and land use agencies to realize sustainability, livability, and equity outcomes.

This section starts with a discussion of Caltrans' own Smart Mobility Framework (SMF) Implementation project conducted between 2012 and 2014, highlighting the work by Caltrans and LA MTA to develop place typologies to better understand the performance of urban places in terms of levels of transportation and land use coordination. It then discusses the development of a new place typology based on Caltrans' own SMF place typology. Through reaching an understanding of this performance, we can determine the best policy pathways going forward to realize sustainability, livability, and equity. An overview of the Smart Mobility Framework here will help provide the necessary context to understand the underlying mechanisms in the Smart Mobility Calculator.

For more on this, and a detailed discussion of the results of a practitioner survey, see the Appendix.

\section{IMPLEMENTATION FRAMEWORKS TO COORDINATE TRANSPORTATION AND LAND USE IN DECISION-MAKING PROCESSES}

Building on the definitions and frameworks discussed above, this report can help agencies such as Caltrans achieve transportation and land use coordination by informing decisions on both sides of the transportation and land use equation.

\section{Place Types and Measurement Constructs}

Between 2012and 2014, Caltrans embarked on two Smart Mobility Framework Implementation projects: one in Southern California and one in Northern California. This section reviews and reflects on some of the main components of SMF (Smart Mobility Framework) and its implementation in Southern California. As shown in Figures 16 and 17, there appears to be a clear association between (a) the SMF place types framework and (b) LA MTA's Accessibility Clusters, as part of LA MTA's Metro Countywide Sustainability Planning Policy.

Figures 16 and 17 show key components of both the SMF and Metro place type frameworks that can be used to identify areas with the greatest potential to evolve into more sustainable places. Looking at Figures 16 and 17 below, it can be seen that they both use a similar $2 \times 2$ matrix with some measure of regional accessibility along the horizontal axis: SMF uses Regional Accessibility, while Metro has developed a similar measure, Job Centrality. Where they slightly differ is that they both have local-level measures, but in the case of Metro, Population Density is used, while the SMF uses Strong Community Design. 


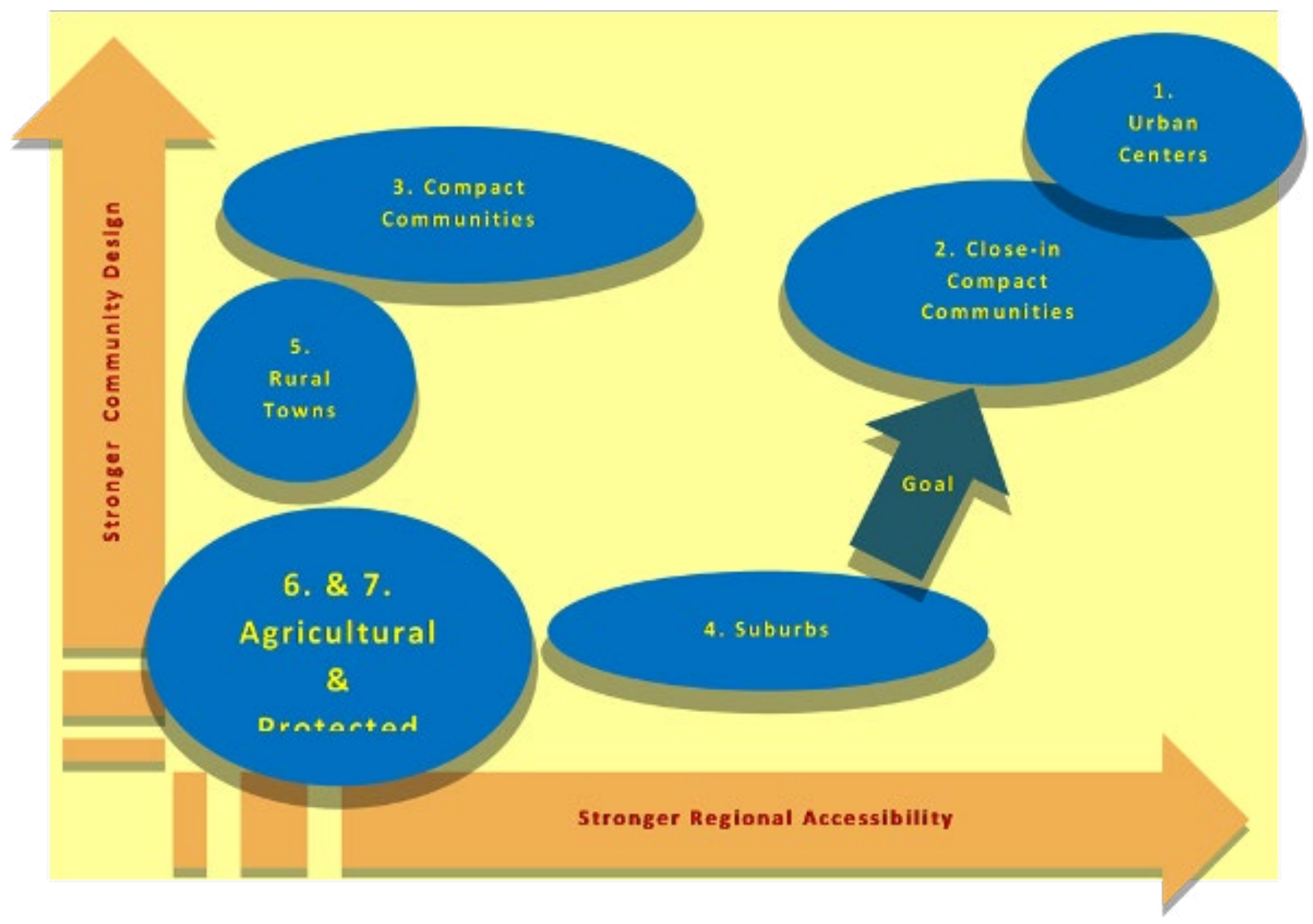

Figure 16. Smart Mobility Framework

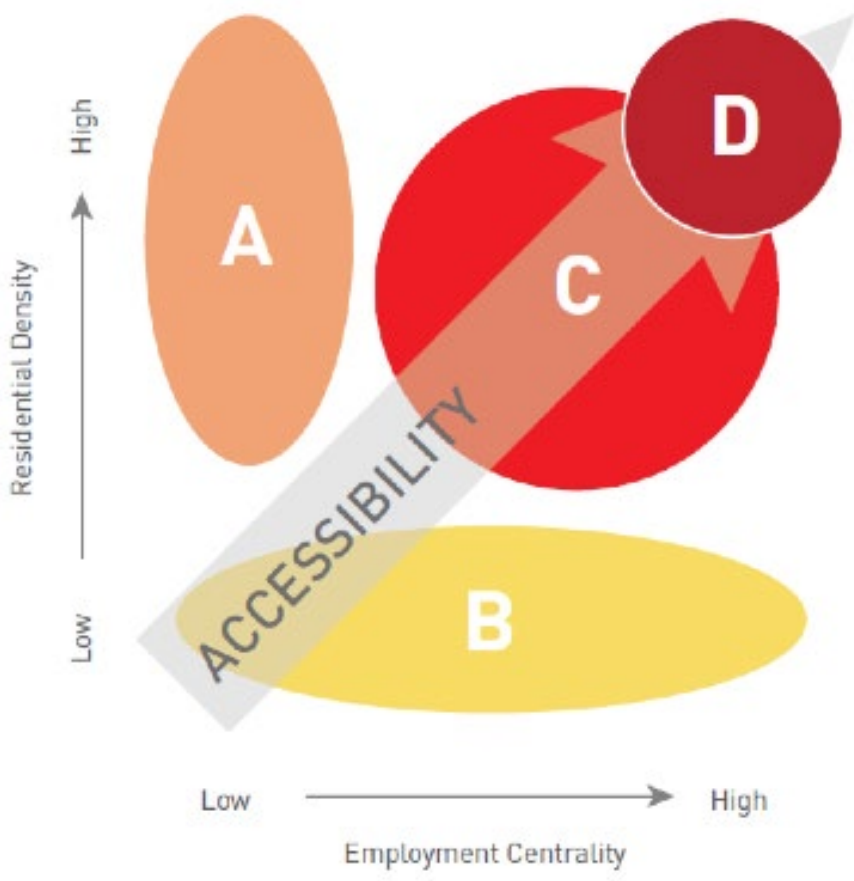

Figure 17. Metro Place-Type Framework 
In both cases, there is an attempt to present what is happening at the local level to determine which areas can facilitate Local Accessibility (which should include non-motorized Transportation facilities) to be cross-referenced with Regional Accessibility. And while Population Density is a coarse proxy, Community Design can be somewhat elusive, but not impossible to measure - the authors would recommend a combination of walkability (intersection density and network connectivity) and local access to jobs and services, which can be found in something like the network-based measure WalkScore.

Building on frameworks and measures discussed herein, the research team can help agencies such as Caltrans achieve transportation and land use coordination by informing decisions on both sides of the equation. For illustration purposes, it is possible to build from Metro's Accessibility Clusters concept as part of work on the Smart Mobility Framework Implementation project. Figures 18 and 19 depict key accessibility clusters of the Metro place type framework, alongside how they were identified in the Hawthorne Study Area as part of the Smart Mobility Framework Implementation project in Southern California.

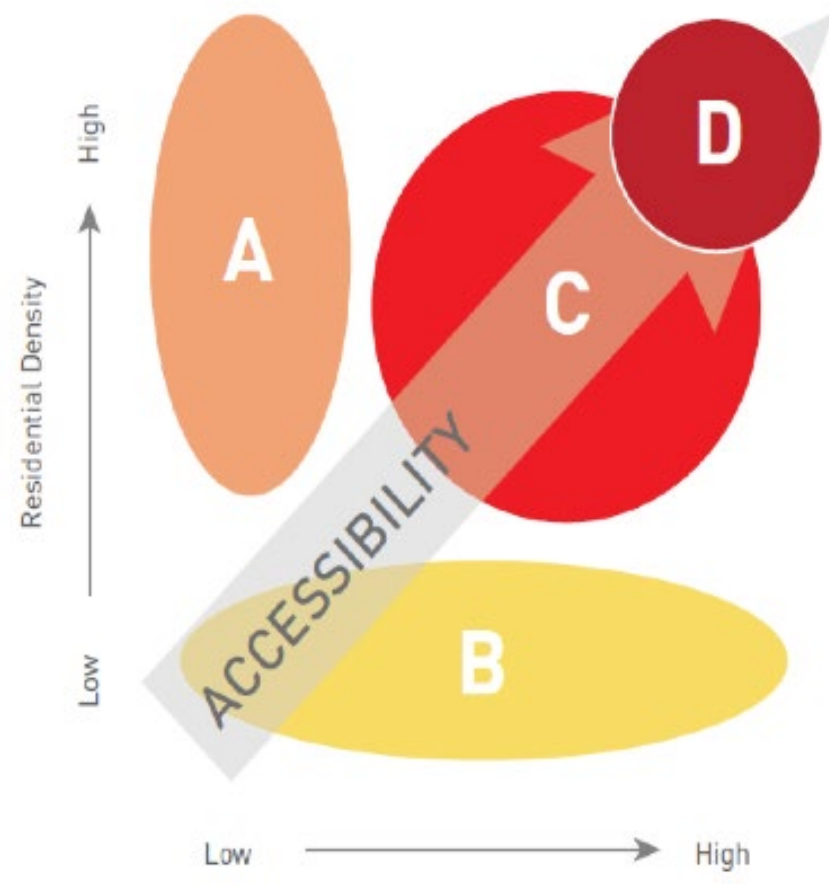

Figure 18. Metro Place-Type Framework 


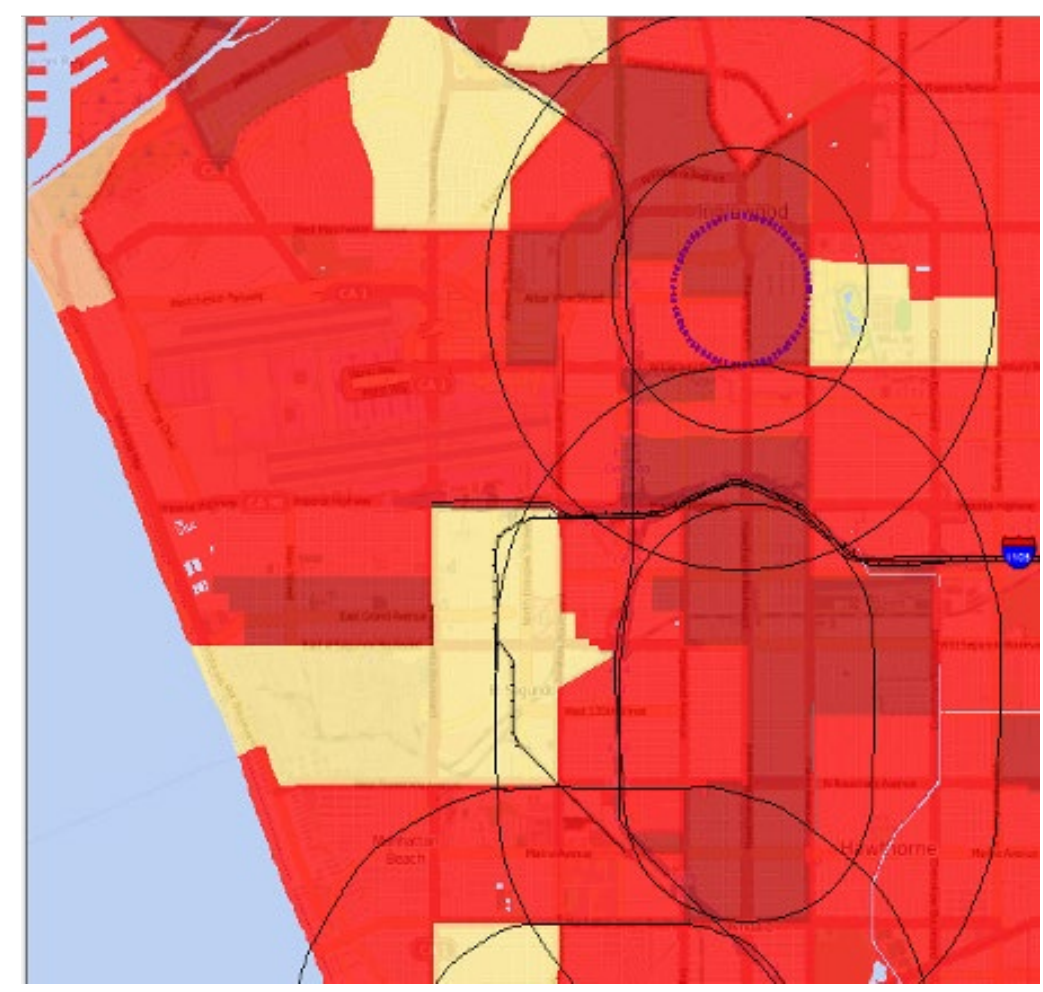

Figure 19. Accessibility Clusters of the Metro Place-Type Framework in the Hawthorne Study Area

\section{Creating and Mapping a Place Typology Based on Location Efficiency and Neighborhood Design (LEND)}

If both the LAMTA and Caltrans SMF frameworks are to be distilled into two key components, they could be Location Efficiency (a regional scale measure) and Neighborhood Design (a local scale measure). Therefore, building on experiences working on the SMF Implementation project, the principal researcher developed a Location Efficient Neighborhood Design (LEND) place type index. The maps and legend are shown in Figure 20. 

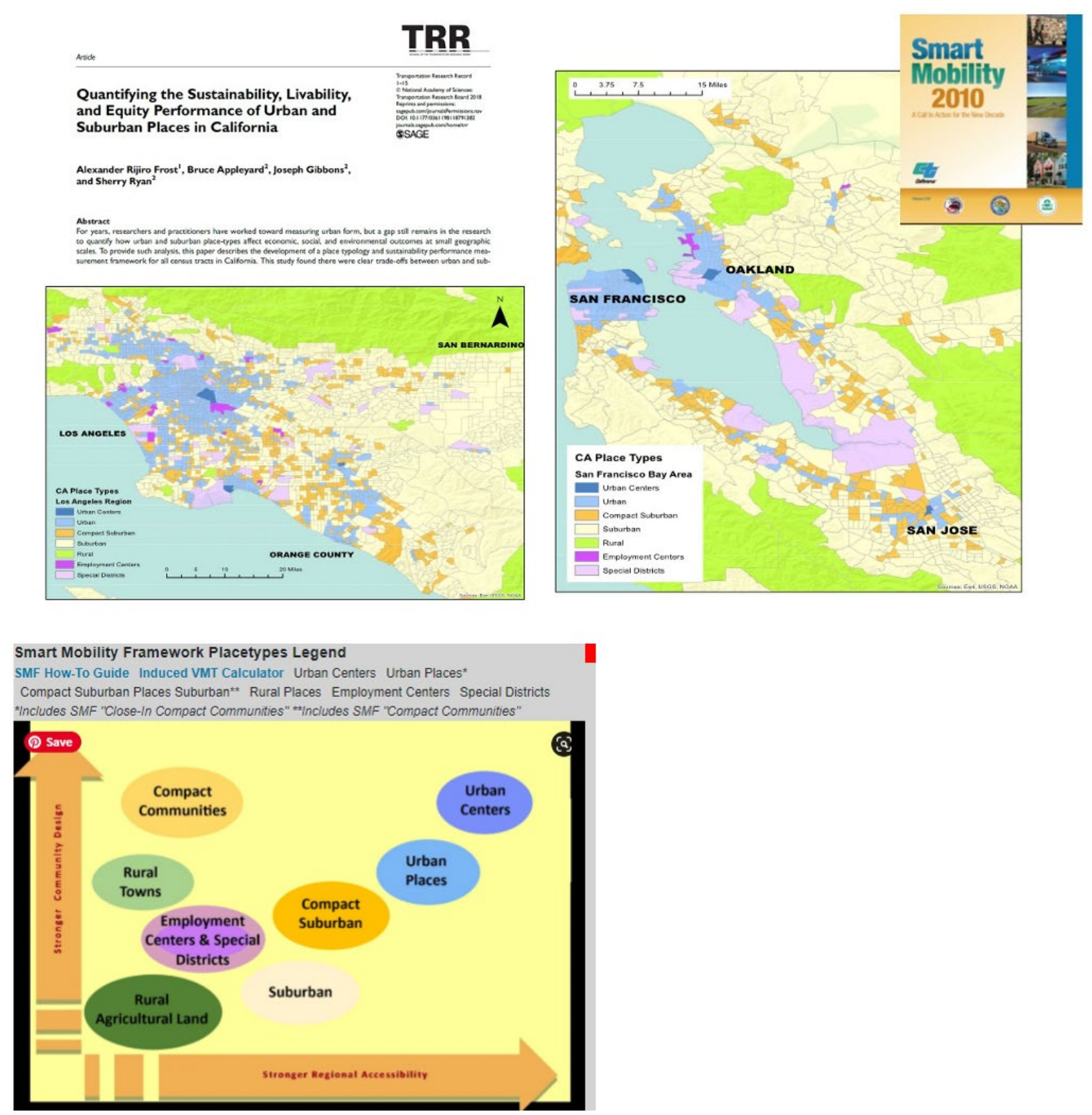

Figure 20. Maps and Legend Based on Location Efficient Neighborhood Design (LEND) for Smart Mobility Framework Place Typology

These GIS databases have been included in the Smart Mobility Calculator and provided to Caltrans with the intention of Caltrans using them for Smart Mobility Framework implementation and corridor planning going forward.

Figure 20 shows key components of the Location Efficient/Neighborhood Design Framework that can be used to identify areas with the greatest potential to evolve into more sustainable places. Looking at the graphic above, a similar matrix to both LA MTA's CSPP and Caltrans SMF, with a dimension for regional accessibility (Location Efficiency) along the horizontal axis, and Neighborhood Design along the vertical axis. As SMF suggests using a measure 
of Regional Accessibility, while Metro recommends using a similar measure, Job Centrality, the SM Calculator (https://smartmobilitycalculator.netlify.app/), provides the measure of Jobs Accessible within a 45-minute transit trip. The authors recognize that also providing a measure of Jobs Accessible within a 45-minute auto trip would be useful in conveying the VMT reduction benefits of both regional access and centrality (Cervero \& Duncan 2003).

\section{Using the SM Calculator to Implement the SMF: Toward the Coordination of Transportation and Land Use}

This section introduces a general approach to apply the Smart Mobility Calculator, specifically its use of VMT per capita and household to understand places in a region, with the aim being to guide Caltrans' policies to improve transportation and land use balance and coordination, both within and outside the organization. It also provides guidance for how the Smart Mobility and Livability Calculators can be used in Caltrans' new corridor planning processes.

Building on frameworks and measures discussed above with LAMTA's CSPP and Caltrans' SMF, it is possible to use the Smart Mobility Calculator (https://smartmobilitycalculator. netlify.app/) developed by the research team, as well as the data the authors are working with related to the Location Efficient Neighborhood Design (LEND) Index to help agencies such as Caltrans, MPOs, and local land use authorities achieve better transportation and land use coordination and, by extension, achieve a host of sustainability, livability, and equity outcomes.

\section{Brief Overview of the Smart Mobility Calculator}

VMT per capita, by census block group, is the first layer that shows up when you open the SM Calculator. VMT per capita is used as it is one of the most important measures for key issues we are dealing with, such as housing, climate action planning, and the new environmental regulations replacing LOS with VMT as per SB 743.
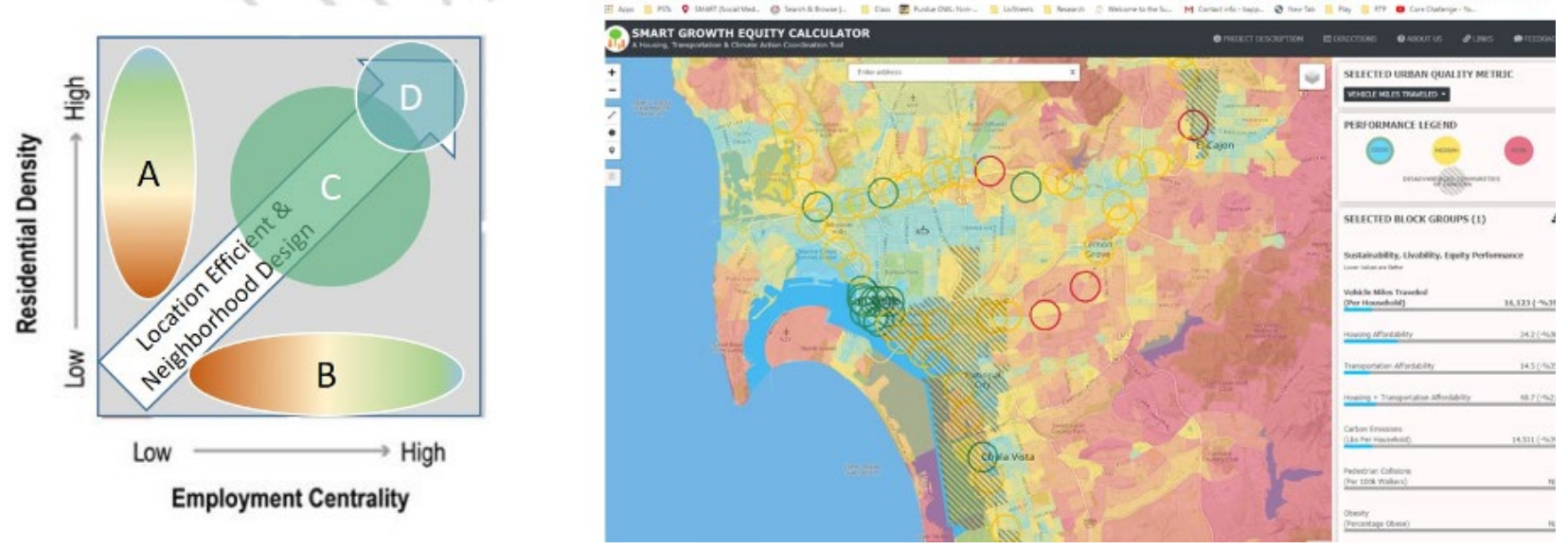

Figure 21. Location Efficient/Neighborhood Design Framework and Smart Growth Calculator

Figure 21 shows key components of the Location Efficient/Neighborhood Design (LEND) framework that can be used to identify areas with the greatest potential to evolve into more 
sustainable places. Looking at the graphic above, it has a similar matrix to both LA MTA's CSPP and Caltrans SMF with a dimension for regional accessibility (Location Efficiency) along the horizontal axis, with Neighborhood Design along the vertical axis. The map in Figure 21 shows a representation of VMT-based place types, as indicated in the SM Calculator, with hot reddish colors showing areas of high VMT (20-28,000 VMT per capita) and cool, blue/green colors showing places with low VMT per capita (15-18,000 VMT per capita). As discussed below, both the graph and the map have the ability to guide policy, specifically related to the coordination of transportation and land use.

\section{The Importance of Transportation and Land Use Coordination as a Function of Accessibility between Homes and Jobs, Lowering Vehicle Miles Travelled (VMT)}

Measures of job and housing accessibility embody the two key characteristics of the transportation/land use equation with the following two components: (a) proximity (how close activities are, mostly determined by land use planning); and (b) mobility (how quickly and easily one can use the transportation system to arrive at a chosen destination). The greater the access between housing and jobs-which is largely a function of transportation/land use coordination-the lower the amount of vehicle travel (Boarnet and Wang, 2018; Cervero and Duncan, 2006)"source":"escholarship.org","abstract":"To achieve the greenhouse gas emission reduction goals established by California Assembly Bill 32 and California Senate Bill 375 will require policy approaches that address the link between land use and vehicle travel. The extensive literature on land use and travel behavior has documented the association between employment access and vehicle miles traveled (VMT. Therefore, in many ways, VMT is a good measure capturing the underlying coordination and balance, or lack thereof, between transportation and land use coordination. More guidance is provided below.

\section{Location Efficiency}

For Location Efficiency, Caltrans' SMF suggests using a measure of Regional Accessibility, while Metro's CSPP recommends using a similar measure of Job Centrality. The SM Calculator provides the measure of Jobs Accessible within a 45-minute Transit Trip. The authors recognize that additionally providing a measure of JobsAccessible within a 45-minute Auto Trip would be useful in conveying the VMT Reduction benefits of both access and centrality (Boarnet and Wang, 2018; Cervero and Duncan, 2006)"source":"escholarship. org","abstract":"To achieve the greenhouse gas emission reduction goals established by California Assembly Bill 32 and California Senate Bill 375 will require policy approaches that address the link between land use and vehicle travel. The extensive literature on land use and travel behavior has documented the association between employment access and vehicle miles traveled (VMT).

\section{Neighborhood Design}

Along the vertical axis is the dimension of Neighborhood Design, which is meant to capture what is happening at the local level-ostensibly to determine which areas can facilitate local accessibility through NMT modes (walking, bicycling, transit, scootering, etc.). 
For local-level measures, LA MTA's CSPP uses Population Density, while the SMC uses a more comprehensive "Community Design." In both cases, the goal is to present what is happening at the local level to determine which areas can facilitate walk- and bike-ability and local accessibility to be cross-referenced with Regional Accessibility. The authors recommend using a combination of walkability (intersection density and network connectivity) and local access to jobs and services, which can be found using network-based Walkscore-which are all provided in the dashboard readout of the Smart Mobility Calculator.

\section{Informing Transportation Decisions}

On the transportation side, measures of Location Efficiency (centrality and regional access, mostly to jobs) as well as Neighborhood Design (high intersection density for route directness \& walkability, WalkScore for local access, and/or population density) help identify the important locations for transportation investments to meet local and regional connectivity needs. In other words, these measures help identify where we should be focusing investments for human-scale transport connectivity (walking, bicycling, transit).

\section{Informing Land Use Decisions}

This information is also useful in informing land use decisions. Location Efficiency (Centrality and Regional Access-mostly to jobs) reveals the areas accessible to jobs. High job access locations should be where the highest population densities are located (with better walking and bicycle facilities). Therefore, a highly Location Efficient (centrally located, regionally accessible) area with a low population density would indicate where more population (dwelling units) should be constructed. Conversely, high population density areas (Neighborhood Design) with low location efficiency are areas that need more jobs and other important activities. 


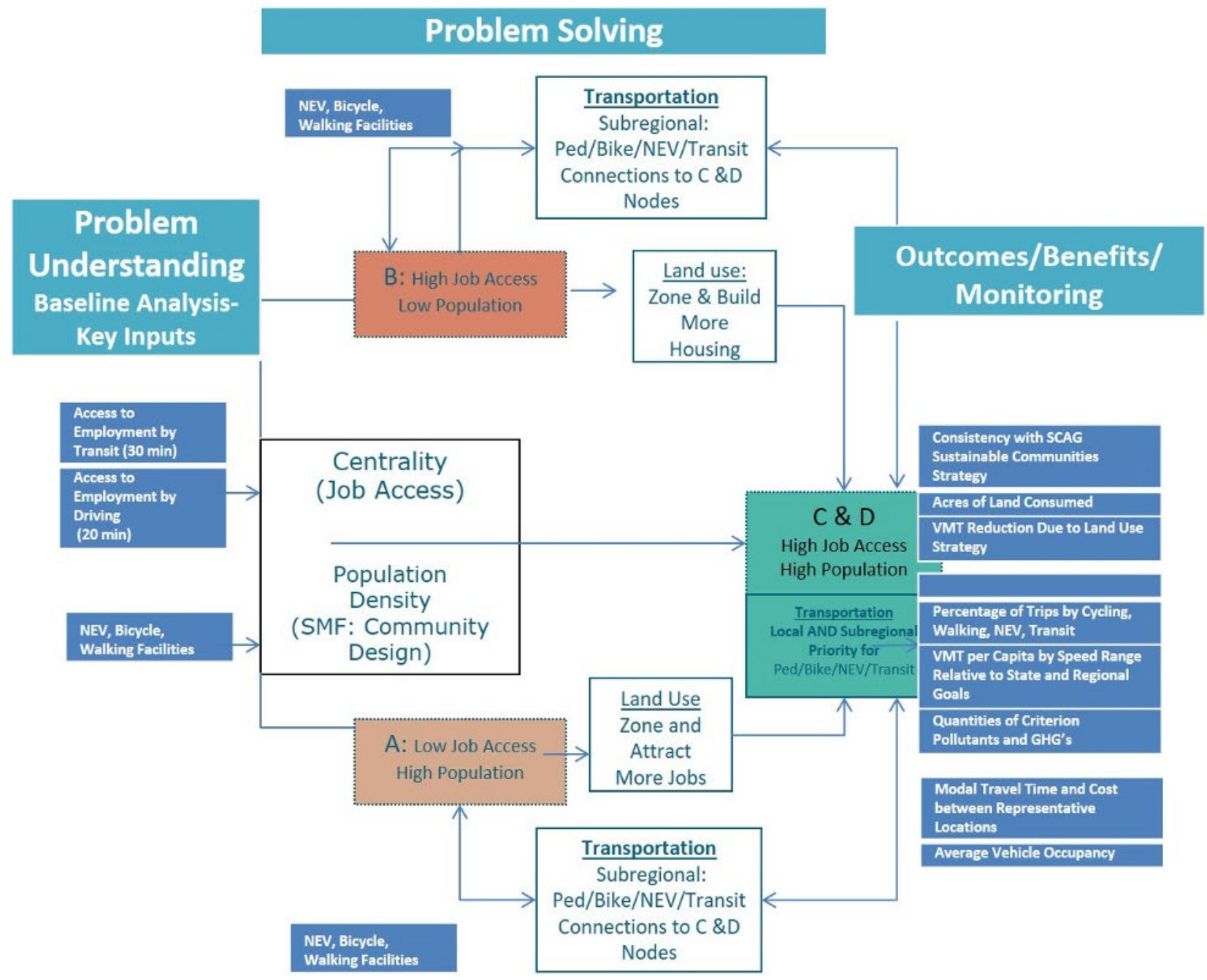

Figure 22. Basic Framework for Transportation and Land Use Decisions Using the LEND Clusters Concept

Building on the preceding discussion, Figure 22 provides a basic policy decision tree for transportation and land use actions using the LEND Framework with the SM Calculator. (This could also be used for both Metro's CSPP and Caltrans' Smart Mobility Frameworkjust the color coding needs to change.)

\section{Cluster/Nodes A}

In clusters with low levels of Location Efficiency (low regional access to jobs) with a moderate to high population density requires zoning to attract more jobs. Occupationally matching the jobs and housing balance is the best way to lower VMT (Cervero, Rood, and Appleyard, 1999; Cervero and Duncan, 2006). On the transportation side, look to make some regional connections to the C\&D nodes. 


\section{Cluster/Nodes B}

On the other hand, high Location Efficiency (Centrality or Regional Access to Jobs) but low Neighborhood Design (low population density), as shown in Accessibility Cluster $\mathrm{B}$, requires actions such as zoning to increase population and housing density. On the transportation side, seek to form some sub-regional connections between the nodes, especially connecting to the C\&D nodes, using sustainable modes, such as transit, bicycling, walking, or person-sized vehicles PSVs (scooters).

\section{Cluster/Nodes C\&D}

For the C\&D nodes that balance Location Efficiency to jobs and high Neighborhood Design (high population density and walkability), prioritize transportation projects that increase both internal (local) and external (regional) connectivity, focusing on sustainable modes, such as transit, bicycling, walking, and person-sized vehicles PSVs (scooters).

\section{The Big Picture}

Before the section wraps up, Figure 23 provides a conceptual meta-view of the ecosystem of performance measures, their production, and finally their application in terms of policies and actions. Oftentimes the agency which gathers and produces the measure, such as the MPO, is not able to put it into action for a more sustainable future. Therefore, there is a very important process of knowledge transfer that should occur. A measure dealing with the number of jobs accessible by transit relies on multiple agents to achieve a sustainable outcome: transit service providers, local traffic engineers, and perhaps more importantly, local land use planners. 


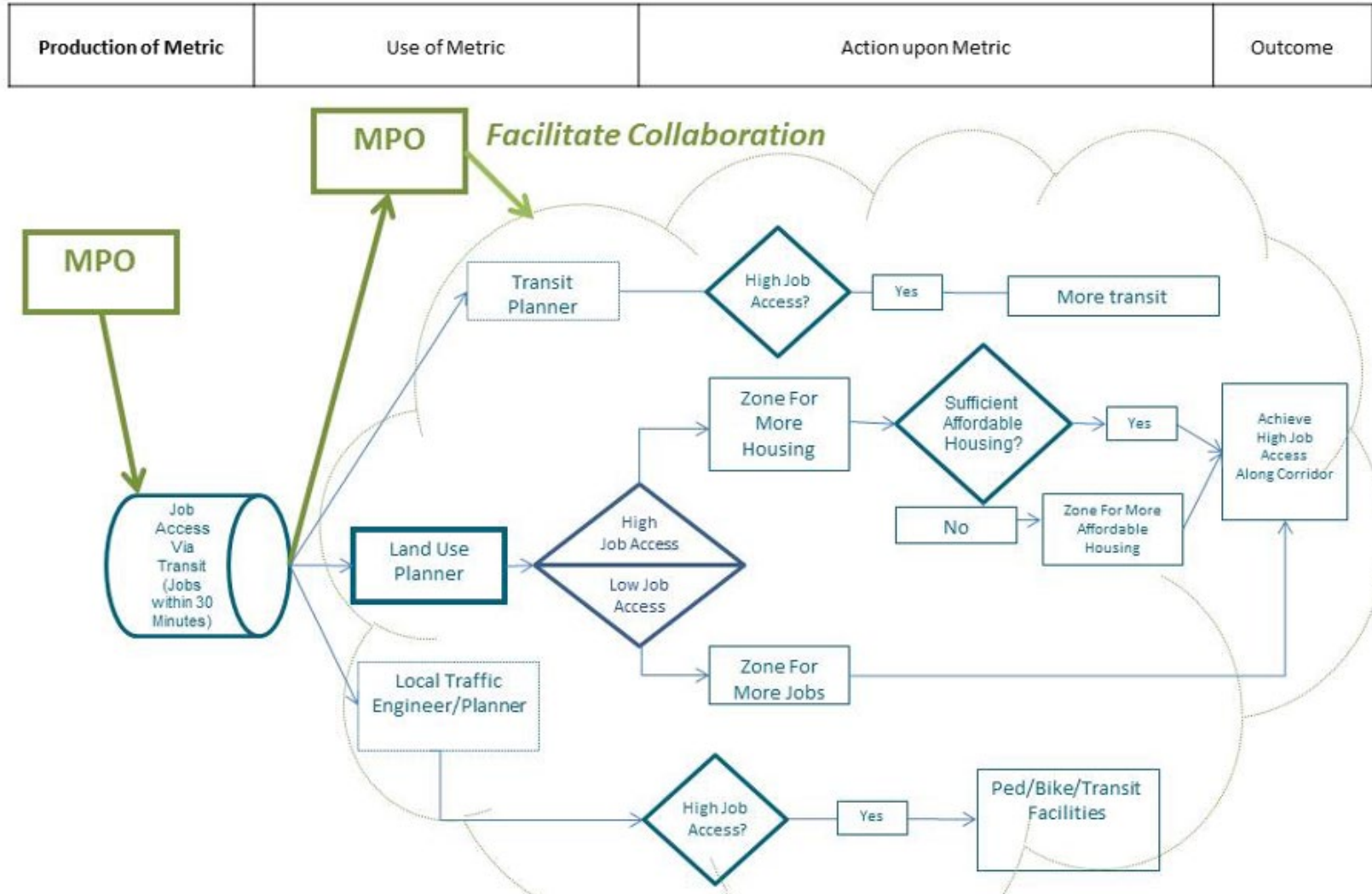

Figure 23. Conceptual Meta-View of the Ecosystem of Performance Measures, Their Production, and How They Can be Applied

\section{WORKING WITH KEY PROFESSIONALS: JOINT STAKEHOLDER MEETING WITH SANDAG AND CALTRANS}

On June 4, 2019, a joint stakeholder meeting between SANDAG and Caltrans Headquarters and District 11 Staff was held to present the above discussion of place types, frameworks, and how tools, including the Smart Mobility Calculator, could be used to better coordinate transportation and land use for sustainability, livability, and equity (SLE) outcomes.

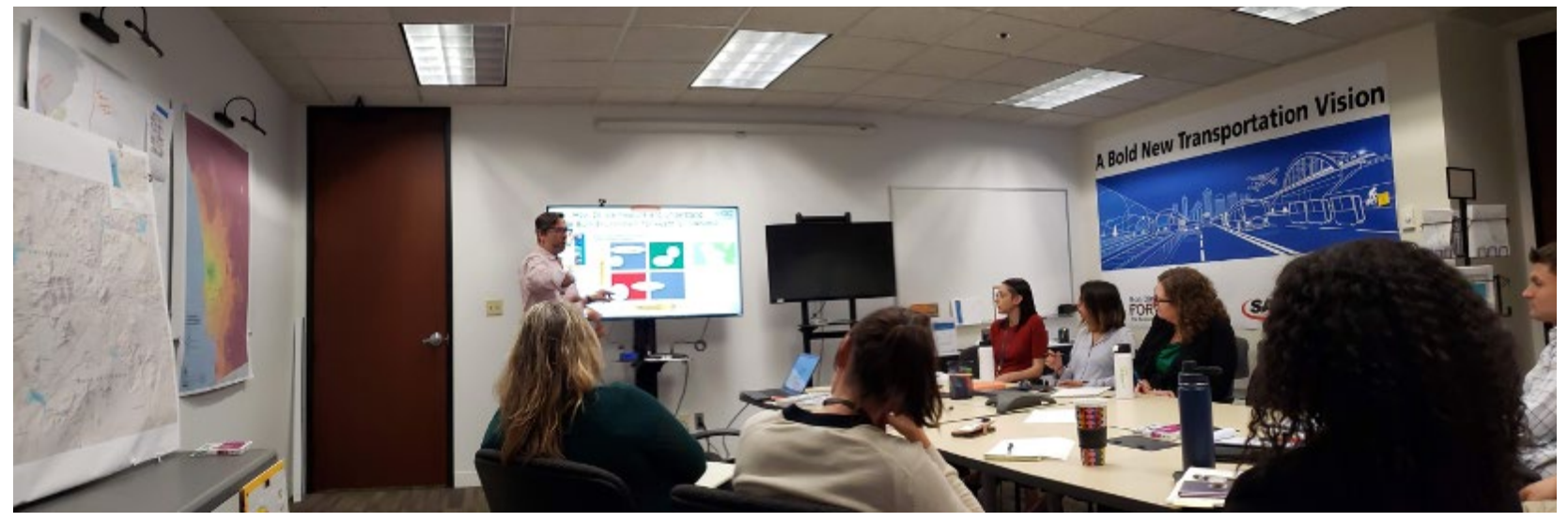

Figure 24. Joint Stakeholder Meeting with Caltrans and SANDAG 


\section{Attendees:}

Phone/ Conference call

Greg Martin

Ann Fox (Caltrans)

Tyler Monson (Caltrans)

Barbara Valentine (Caltrans)

+1 other

$\underline{\text { In Person/room }}$

Allison Wood

Krystal Ayala

Marissa Meghan

Tracy Forshaw

Rachel Cortez

David Flight

Pat Landram

Dave Kedrow

There was general consensus in this meeting about the lack of coordination between land use and transportation that both Caltrans and SANDAG have to deal with. One participant lamented SANDAG's lack of land use authority, and that some cities don't want to "play ball." Sentiments were also expressed that both MPO and member agencies get penalized in California for not meeting climate goals.

There was general agreement and support that the tools and frameworks presented could help the coordination of transportation and land use planning by MPOs and Caltrans, working in partnership with local land use authorities.

Specifically, the following points were made:

- It is helpful to communicate the benefits to the public-and make economic arguments for different scenarios.

- If areas are shown to change their urban form (increase density, adding transit lines), showing the VMT/Transit/Health metrics is useful to show the public.

- The transparency provided by the SM Calculator is useful in working with all stakeholders. 
- The SM Calculator is useful in how it allows you to draw corridors, then output these ballpark figures on sustainability, livability, and equity.

- Another useful feature would be to show scenarios with things like added transit lines, and then using the calculator to calculate changes in ridership/VMT/etc.

This feedback shows how transportation and land use coordination is an identified issue that needs to be addressed by Caltrans and MPOs working with local governments who have authority over land use. The Smart Mobility Calculator was also appreciated for its accessibility to a wide range of users and for how it can be used for corridor planning, especially in the early stages.

According to Caltrans' own official review of the Smart Mobility Calculator:

- The Calculator has very good functionality to show the Daily VMT (Per Capita, Per Employee, Per Capita for Home Base Work) which is helpful for Climate Action Planning, and evaluating the Environmental Impacts of development projects under SB 743. It uses Caltrans' official VMT numbers (per capita and per employee) that can be used to guide policies for Caltrans and its partners.

- By showing how much an area's VMT is above or below the regional average, the Calculator can be used to apply SB 743 CEQA project analysis parameters (which allows for environmental streamlining of significant developments at or below $-15 \%$ of the regional average).

- In addition to VMT, the Calculator includes a number of other urban quality metrics related to environmental impacts, affordability, health, and social equity. Included metrics are Housing and Transportation Affordability, Dwelling Density, Population Density, Job Density, Carbon Emissions, Pedestrian Collisions, Job Accessibility, Walkability, Walking Percent, Obesity, and Cardiovascular Disease.

- Climate action planning: The tool shows how many pounds of carbon per household will be generated from travel in different locations in the region and can be used to calculate different development scenarios.

- New housing initiatives: This tool can help new housing initiatives (such as SB 50 ) by showing the areas that are in close proximity to transit. The circles show half mile catchment areas around transit stations using the high (green), medium (yellow), low (red) smart growth performance typology, based on a national study of urban quality of the National Academies of Sciences.

- It also shows the location of disadvantaged communities, per SB 535, which is key to then being able to inform communities they should enact community planning processes to handle new growth and avoid displacement that could come with gentrification. 


\section{CONCLUSION}

Performance measures and planning support tools are useful only insofar as they help inform agency decisions about future policies, plans, and investments. In particular, performance measures should be defined and measured in order to help communities understand tradeoffs and benefits toward achieving sustainability, livability, and equity outcomes. Most regions continue to use transportation system performance measures that are dominated by congestion and mobility measures, although this is now changing in California with initiatives like SB 743.

A major purpose of this report is to help agencies make better, more coordinated transportation and land use decisions. While it would be ideal to have transportation and land use decisions all made by one agency, they are currently led by different agencies operating at different scales and time frames. Therefore, we are left to develop frameworks and tools to better measure, understand, and then act to realize sustainability, livability, and equity. The corridor level is an ideal scale where transportation and land use agencies can work together. Departments of Transportation like Caltrans should embrace their role as ambassadors to work with local land use authorities to organize efforts at the corridor scale. To be effective, all parties should adopt a broader, more empathetic understanding for each other's perspective and use the tools and measures collectively, as can be done with the Smart Mobility Calculator. If both sides of the transportation and land use equation start to work with each other's perspective, tools, measures and policy perspective, then we have a better chance of achieving sustainable, livable and equitable outcomes. As travel is a derived demand to get from one place to another, it is helpful to remember that a good regional land use plan can be a great regional transportation plan.

In summary, these frameworks and tools should be employed to:

1. Create context-sensitive and inclusive processes to help stakeholders and a community understand what it takes to become more sustainable, livable, and equitable;

2. Help understand what is important to measure and analyze in current conditions and future scenarios;

3. Screen, prioritize, and mediate policies in support of increasing a diverse and complementary set of opportunities for people to realize greater community sustainability, livability, and equity; and

4. The tools should be clear, intuitive, and relevant to the stakeholders using them. 


\section{APPENDIX}

\section{GOING FORWARD: A FRAMEWORK FOR MEASURING, UNDERSTANDING, AND REALIZING TRANSPORTATION AND LAND USE COORDINATION}

The recommendations in this Appendix build on the authors' review of work on the SMF Implementation Process for the SBCC, Caltrans, LAMetro, and SCAG, and their respective CSPP/SMF processes.

In sum, informing agency decisions should be the driving force behind measures, approaches, study areas, etc. A major purpose of this work is to help agencies make better, more integrated transportation and land use decisions. While it would be ideal to have transportation and land use decisions all made by one agency, they are led by different agencies operating at different scales and over different time frames. Therefore, it is important to discuss ways to integrate these decisions through the existing processes of the institutions and their various measures. But first, it is necessary lay some groundwork regarding how we should think about performance measures.

\section{Understanding the Various Roles of Performance Measures}

When considering the use of performance measures in transportation and land use planning, there are a few aspects that should be considered: What? Why? and finally, Who?

“What?" refers to "what do the measures tell us?" including their associations, causal relationships, and the context that they convey.

\section{Associations and Causal Relationships}

Basically, what do the measures communicate? In other words, what can be established either from the body of empirical research, or from theory about the association that measures have to policy, as well as to each other? For example, research tells us that regional accessibility/ centrality is often associated with lower VMT and vehicle use (Ewing and Cervero, 2010 and 2010b)update earlier work, include additional outcome measures, and address the methodological issue of self-selection. Methods: We computed elasticities for individual studies and pooled them to produce weighted averages. Results and conclusions: Travel variables are generally inelastic with respect to change in measures of the built environment. Of the environmental variables considered here, none has a weighted average travel elasticity of absolute magnitude greater than 0.39 , and most are much less. Still, the combined effect of several such variables on travel could be quite large. Consistent with prior work, we find that vehicle miles traveled (VMT. Associations can also refer to which measures interact with each other (see example below).

\section{Context (Place Type)}

This means asking questions about the environment and scale, including built form, the transport facilities (e.g., street design, light rail facility, freeway), socio-demographics, and so on. Basically, what type of place are we talking about? 
As an illustration, combining Associations and Context can indicate that if an area has a high centrality rating, one should expect lower VMT. If this is not the case, then something is missing: perhaps the facilities for non-auto travel. This is critical, as many of even our best scenario planning models and tools do not do much in the way of appreciating new facilities for bicycles, pedestrians, or even such new modes as neighborhood electric vehicles. The MXD model developed by Ewing et al. (2013), for example, is limited to measuring intersection density, which-while effective-is a rather coarse measure of pedestrian/bicycle facilitation (Ewing et al., 2011).

\section{“Why?"}

This question essentially refers to the purpose of the measure. Once the Associations and the Context within which these measures are being applied are understood, the next aspect to be considered is for what Purpose the measures will be used.

What is the measure going to be used for? What are the purposes of the measure? There are at least four purposes for which a measure can be used, as follows:

- Benchmarking/assessment (diagnosis)

- Policy decision making (prognosis)

- Forecasting

- Monitoring

\section{"Who?"}

Finally, perhaps the most important element for implementation is asking who the best agencies are to generate, disseminate, and/or act upon these measures. Who are the agencies and stakeholders who will use these data, and what is the decision ecosystem in which the measures could be applied? The following are common stakeholders and their areas of interest:

- Transportation agencies are concerned with access along corridors generally and have specific concerns relating to transit ridership levels, capital investment decisions, and ongoing operational decisions across various modes at the local and regional scale.

- Municipal governments set land use designations and standards for private development and also have direct authority over local streets and infrastructure. Municipal policies further relate to housing, economic development, and other dimensions of livability.

- State departments have the responsibility for complementary policies pertaining to transportation, housing, the environment, economic development, and social services. 
- Private developers and business interests deliver most non-government investments, including most forms of development within regulatory limits and procedures.

- Advocacy groups represent an array of concerns that may focus on a locale (for example, community groups) or a specific interest (such as affordable housing or bicycling).

- Community members who live or work in the areas are central stakeholders, regardless of whether they are represented by an organization.

Building on the above is a discussion, here is a set of performance metrics that were recommended for this project. First, they were based on the SMF performance measures and compared to the performance measures used by Metro in the Long Range Transportation Plan (LRTP) as well as by SCAG for the RTP/SCS. In selecting the performance metrics, the intent was to identify a subset of the SMF measures that would be most meaningful in demonstrating the sustainability policies at the sub-regional scale. The authors' approach was built from the six overarching SMF Principles. They are as follows:

- Location Efficiency

- Reliable Mobility

- Health and Safety

- Environmental Stewardship

- Social Equity

- Robust Economy

Alongside these principles were 17 SMF performance measures and their recommended metrics, as described in Exhibit 11 of the Smart Mobility 2010: Call to Action.

The authors' initial assessment was that these SMF measures require that significant planning analysis infrastructure (e.g., regional travel demand models) already be in place (and accessible) to support the computation of all 17 performance measures, and SMF requires significant investment of professional effort to perform the computations for a variety of possible transportation improvement projects.

Below are the principles from the CSPP and the SBCCOG.

CSPP principles:

- Connect people and places

- Create community value

- Conserve resources 
SBCCOG Sustainable South Bay (SSB) principles:

- Reduce criteria pollutants

- Reduce congestion

- Reduce gasoline consumption

- Improve safety

The specific metrics that are recommended below are intended to be supportive of these principles as well as the overarching principles of the Smart Mobility Framework.

The CSPP uses 15 performance measures in support of the three broad CSPP principles to evaluate projects. Performance measures from CSPP are used for monitoring purposes at the regional level rather than for evaluation or prioritization, but some of them could be appropriate for sub-regional analysis. Additional project-based metrics were developed through consultant efforts related to the CSPP; these are meant to be used to compare the performance of different project alternatives rather than to compare and prioritize different projects as part of a sub-regional planning effort. Table 1 lists the metrics used by the CSPP and the SBCCOG.

In addition, the SBCCOG has identified several strategies for sustainable development that would not generally score very well using traditional performance measurement packages, which are often focused on measuring increased system performance for automobiles.

Table A1 summarizes the recommended performance metrics, tools, and data sources. 
Table A1. Recommended Performance Metrics

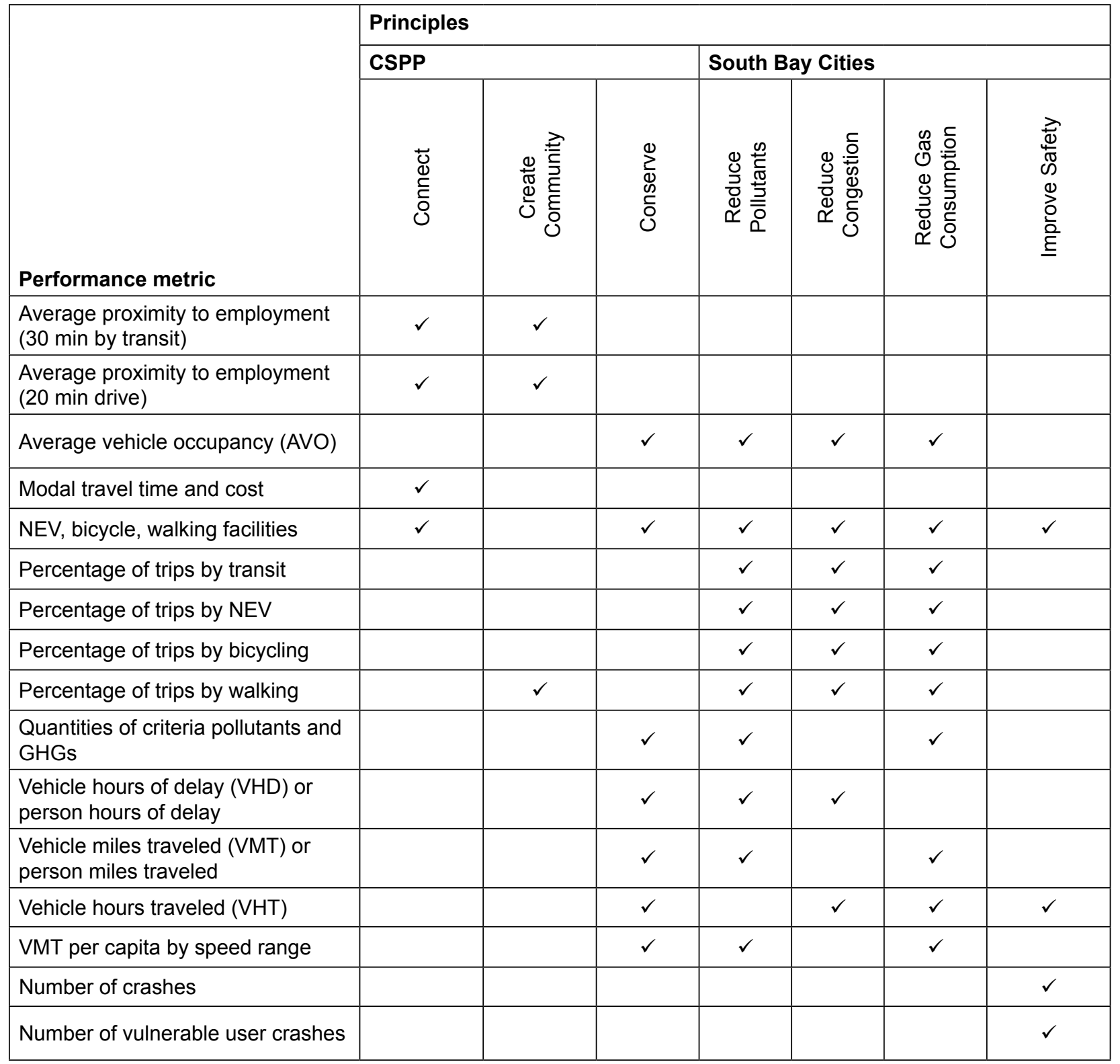

\section{Further Review of Online Planning Support Tools}

The California Healthy Places Index aggregates health-related information about census tracts in California and integrates them (along with other health indicators) into an HPI (Healthy Places Index) score. The map is unique in that multiple individual health or nonhealth metrics can be overlaid on the base map, allowing for quick assessment of individual metrics' influence on the overall HPI score. The map has a well-defined color scheme and outlines census tracts that the mouse hovers over, along with a quick reference for determining the score range of a certain color.

The CNT's H + T Index tracks housing and transportation costs as a percentage of income for searched locations, with a wide range of granularities ranging from Metropolitan Planning Organization level to Census Block Group level. The index not only visually presents 


\section{ABBREVIATIONS AND ACRONYMS}

\begin{tabular}{ll}
\hline CSPP & LA MTA's Metro Countywide Sustainability Planning Policy \\
DOT & Departments of Transportation \\
EPA & Environmental Protection Agency \\
HH & Household \\
LA MTA & Los Angeles County Metropolitan Transportation Authority \\
MPO & Metropolitan Planning Organization \\
SBCCOG & South Bay Cities Council of Governments \\
SCAG & Southern California Association of Governments \\
SMC & Smart Mobility Calculator \\
TLC & Transportation and Land Use Coordination \\
VMT & Vehicle Miles Traveled \\
\hline
\end{tabular}


affordability data in a map, but also presents information graphically and as a percentiles chart. Data at any granularity can be accessed as a "fact sheet" that highlights important metrics and factors that influence the overall level of affordability. The online map quickly provides an affordability number for quick assessment, but the detailed information behind affordability is easily downloaded and provided in a visually appealing and readable format.

All of the maps discussed above are successful in conveying a large quantity of information quickly and easily for the viewer. The Opportunities Atlas relies on separating metrics allowing the viewer to see one set at a time in a non-overlapping manner. On the other hand, the California Healthy Places Index aggregates information into a single index which can then be easily seen on a map. Somewhere along the spectrum of information display is the $\mathrm{H}+\mathrm{T}$ Index, which is data-intensive but offers a level of detail the viewer determines. However, none offer tools to sort data and search based on other pieces of information besides location, nor do they have integrated mechanisms for scenario planning exercises. Some example tools may include: optimal location selection for a given set of parameters, visual data comparison between multiple locations, or location ranking based on data. Additional decision making capabilities are likely beyond the primary purpose of the online maps. 


\section{ENDNOTES}

1. Planning support tools (also called planning support systems) are computer-based applications that assist in urban planning activities by providing access to essential data, models, and spatial analysis methods (Geertman and Stillwell, 2004).

2. The report was actually entitled Our Common Future and was produced by the World Commission on Environment and Development, but it is best known by this title.

3. Some call these the three Es, with the social component being referred to as social equity.

4. Ibid.

5. There are several specific works that show conceptual agreement on defining sustainability in transportation, as follows:

- Black, W. "Sustainable Transport: Definitions and Responses." Integrating Sustainability into the Transportation Planning Process. 2005.

- Litman, T. and D. Burwell. "Issues in Sustainable Transportation." International Journal of Global Environmental Issues 6 (2006): 331-347.

- Zhou, J. Sustainable Transportation: Review of Proposals, Policies, and Programs 2000-2007. 88 ${ }^{\text {th }}$ Annual Meeting of the Transportation Research Board. Washington, DC, 2009. 


\section{BIBLIOGRAPHY}

Ahangari, H., C. Atkinson-Palombo, and N.W. Garrick. Accident Analysis \& Prevention 107 (2017): 77-85.

Appleyard, B. Smart Growth Catalysts Planning 71 (2005).

Appleyard, B., C. Allen, and E. Cordova. Smart Mobility Calculator. Web page, 2018. http://smartgrowthcalculator.herokuapp.com/index.html (accessed December 12, 2018).

Appleyard, B., C. Ferrell, C. Allen, C. Schroeder, and C. Armusewicz. Livability Calculator for the TCRP H-45 Handbook, Building Livable Transit Corridors: Methods, Metrics and Strategies. Transit Cooperative Research Program of the Transportation Research Board. Washington, DC, 2016.

Appleyard, B., C. Ferrell, M. Carroll, and M. Taecker. Toward Livability Ethics.

Transportation Research Record: Journal of the Transportation Research Board 62-71(2014).

Appleyard, B.. New Methods to Measure Urban Environments for Consumer Behavior Research| Individual Access Corridor Analysis of Environmentally Sustainable Travel to Rapid Transit. University of California, Berkeley, 2011.

Appleyard, B., D. Appleyard, Livable Streets 2.0. Elsevier. 2020

Batty, M. "Defining Geodesign (= GIS + Design?)." Environment and Planning B: Planning and Design 40 (2013): 1-2.

Black, W. "Sustainable Transport: Definitions and Responses." Integrating Sustainability into the Transportation Planning Process. 2005.

Boarnet, M., and X. Wang. Accessibility to Jobs Outside Employment Sub-Centers Has a Larger Impact on VMT Reduction than Accessibility to Jobs Inside Employment Sub-Centers. 2018.

Boarnet, Marlon G. and Susan Handy. DRAFT Policy Brief on the Impacts of Residential Density Based on a Review of the Empirical Literature. http://www.arb.ca.gov/cc/ sb375/policies/density/density brief.pdf.

Boarnet, Marlon G., Hsin-Ping Hsu, and Susan Handy. DRAFT Policy Brief on the Impacts of Employer-Based Trip Reduction Based on a Review of the Empirical Literature.2010. http://www.arb.ca.gov/cc/sb375/policies/ebtr/ebtr brief.pdf.

Boarnet, Marlon G., Hsin-Ping Hsu, and Susan Handy. Draft Policy Brief: Impact of JobsHousing Balance on Passenger Vehicle Use and Greenhouse Gas Emissions Based on a Review of the Empirical Literature. 2010 http://arb.ca.gov/cc/sb375/ 


\section{policies/jhbalance/jhbalance brief.pdf.}

Boarnet, Marlon G., Kenneth Joh, Wally Siembab, William Fulton, and Mai Thi Nguyen. Retrofitting the Suburbs to Increase Walking: Evidence from a Land Use-Travel Study. Urban Studies . 2011. DOI: 10.1177/0042098010364859. Cited in Boarnet and Handy [1].

California Air Resources Board. Senate Bill 375: Research on Impacts of Transportation and Land Use-Related Policies. http://arb.ca.gov/cc/sb375/policies/policies.htm.

Caltrans. 2010. Smart Mobility: A Call to Action for the New Decade.

Caltrans. 2020. Corridor Planning Process

Cervero, R. "Integration of Urban Transport and Urban Planning." In The Challenge of Urban Government: Policies and Practices. World Bank, 2001.

Cervero, R., 2003. Growing smart by linking transportation and land use: Perspectives from California. Built Environment 29: 66-78.

Cervero, R., and M. Duncan. Which Reduces Vehicle Travel More: Jobs-Housing Balance or Retail-Housing Mixing?. Journal of the American Planning Association 72 (2006): 475-490.

Cervero, R., T. Rood, and B. Appleyard. Tracking accessibility: employment and housing opportunities in the San Francisco Bay Area. Environment and Planning A 31 (1999): 1259-1278.

Cinelli, M., S.R. Coles, and K. Kirwan. "Analysis of the Potentials of Multi Criteria Decision Analysis Methods to Conduct Sustainability Assessment." Ecological Indicators (2014). http://doi.org/10.1016/j.ecolind.2014.06.011

Dangermond, J. "GeoDesign and GIS—Designing our Futures." In Peer Reviewed Proceedings of Digital Landscape Architecture. Anhalt University of Applied Science, Germany, 2010.

Dowling Associates, Inc. Multimodal Level of Service Measures for Urban Streets. NCHRP Report 616, 2008.

ECONorthwest. Case Study: Testing Application of Integrated Transportation Planning Methods on System Level Evaluation. Report prepared for Puget Sound Regional Council and US Department of Transportation, Federal Highway Administration, June 1996.

ECONorthwest. Integrated Transportation Planning: A Primer for Policymakers. Puget Sound Regional Council. July 1995. 
ECONorthwest. Least-Cost Planning: Principles, Applications and Issues. Report prepared for Office of the Environment and Planning, Federal Highway Administration, US Department of Transportation. July 1995.

ECONorthwest. Technical Memorandum Regarding Procedural and Analytical Issues Associated with Implementing Integrated Transportation Planning. Puget Sound Regional Council. June 1995.

El-Geneidy, A.M., and D.M. Levinson. Access to destinations: Development of accessibility measures. 2006.

Ewing, R., and R. Cervero. Travel and the built environment: a meta-analysis. Journal of the American Planning Association 76 (2010): 265-294.

Ewing, R., M. Greenwald, M. Zhang, J. Walters, M. Feldman, R. Cervero, L. Frank, and J. Thomas. Traffic generated by mixed-use developments-six-region study using consistent built environmental measures. Journal of Urban Planning and Development 137 (2011): 248-261.

Ewing, R., S. Hamidi, J.B. Grace, and Y.D. Wei. Does urban sprawl hold down upward mobility? Landscape and Urban Planning 148 (2016): 80-88.

Exner, J.-P. "Smart Cities-Field of Application for Planning Support Systems in the $21^{\text {st }}$ Century?" presented at the proceedings of the $14^{\text {th }}$ Computers in Urban Planning and Urban Management (CUPUM2015), 2015, 118-131.

Ferrell, C.E., B. Appleyard, and M. Taecker. A Handbook for Building Livable Transit Corridors: Methods, Metrics and Strategies. No. TCRP H-45. Transit Cooperative Research Program, 2016.

Flaxman, M. Fundamentals of Geodesign. Proceedings of Digital Landscape Architecture, 2009, 28-41.

Frederick, C., W. Riggs, and J.H. Gilderbloom. Commute mode diversity and public health: A multivariate analysis of 148 US cities. International Journal of Sustainable Transportation 12 (2018).

Geertman, S., and J. Stillwell. "Planning Support Systems: An Inventory of Current Practice." Computers, Environment and Urban Systems 28 (2004): 291-310. http://doi.org/10.1016/S0198-9715(03)00024-3

Gulden, J., J. Goates, and R. Ewing. "Mixed-Use Development Trip Generation Model." Transportation Research Record: Journal of the Transportation Research Board 2344(2013): 98-106. http://doi.org/10.3141/2344-11

Hamidi, S., R. Ewing, Z. Tatalovich, J.B. Grace, and D. Berrigan. Associations between urban sprawl and life expectancy in the United States. International Journal of 
Environmental Research and Public Health 15 (2018): 861.

Handy, S. International Regional Science Review 28 (2005): 146-167.

Handy, Susan, Gian-Claudia Sciara, and Marlon Boarnet. DRAFT Technical Background Document on Impacts of Pedestrian Strategies Based on a Review of the Empirical Literature. http://www.arb.ca.gov/cc/sb375/policies/ped/ped bkgd.pdf.

Handy, Susan, Gil Tal, and Marlon Boarnet. DRAFT Policy Brief on the Impacts of Bicycling Strategies Based on a Review of the Empirical Literature. http://www. arb.ca.gov/cc/sb375/policies/bicycling/bicycling brief.pdf.

Handy, Susan, Gil Tal, and Marlon Boarnet. DRAFT Policy Brief on the Impacts of Network Connectivity Based on a Review of the Empirical Literature. http://www. arb.ca.gov/cc/sb375/policies/connectivity/netconnectivity brief.pdf.

Handy, Susan, Gil Tal, and Marlon Boarnet. DRAFT Policy Brief on the Impacts of Regional Accessibility Based on a Review of the Empirical Literature. http://arb. ca.gov/cc/sb375/policies/regaccess/regaccess brief.pdf.

Handy, Susan, Gil Tal, and Marlon Boarnet. DRAFT Policy Brief on the Impacts of Telecommuting Based on a Review of the Empirical Literature. http://www.arb. ca.gov/cc/sb375/policies/telecommuting/telecommuting brief.pdf.

Handy, Susan, Gil Tal, and Marlon Boarnet. DRAFT Technical Background Document on the Impacts of Connectivity Based on a Review of the Empirical Literature. http:// www.arb.ca.gov/cc/sb375/policies/connectivity/netconnectivity bkgd.pdf.

Handy, Susan, Gil Tal, and Marlon Boarnet. DRAFT Technical Background Document on Impacts of Regional Accessibility Based on a Review of the Empirical Literature. http://arb.ca.gov/cc/sb375/policies/regaccess/regaccess bkgd.pdf.

Handy, Susan, Gil Tal, and Marlon Boarnet. DRAFT Technical Background Document on Impacts of Telecommuting Based on a Review of the Empirical Literature. http:// www.arb.ca.gov/cc/sb375/policies/telecommuting/telecommuting bkgd.pdf.

Handy, Susan, Steve Spears, and Marlon G. Boarnet. DRAFT Policy Brief on the Impacts of Transit Service Strategies Based on a Review of the Empirical Literature. http:// www.arb.ca.gov/cc/sb375/policies/transitservice/transitservice brief.pdf.

Handy, Susan, Steve Spears, and Marlon G. Boarnet. DRAFT Technical Background Document on the Impacts of Transit Service Strategies Based on a Review of the Empirical Literature. http://www.arb.ca.gov/cc/sb375/policies/transitservice/ transitservice bkgd.pdf.

Jiang, B., B. Huang, and V. Vasek. "Geovisualisation for Planning Support Systems." Planning Support Systems in Practice (2003): 177-191. http://doi. 


\section{org/10.1.1.63.6979}

Lachapelle, U. Public Transit Use as a Catalyst for an Active Lifestyle: Mechanisms, Predispositions and Hindrances. Dissertation. University of British Columbia, 2010.

Lachapelle, U., and L.D. Frank. Transit and health: mode of transport, employersponsored public transit pass programs, and physical activity. Journal of Public Health Policy 30 (2009): S73-S94.

Levine, J., J. Grengs, and Q. Shen. Metropolitan Accessibility and Transportation Sustainability: Comparative Indicators for Policy Reform. Presented at the $5^{\text {th }}$ Urban Research Symposium, Marseille, France, 2009.

Levine, J., J. Grengs, Qingyun Shen, and Qing Shen. Does Accessibility Require Density or Speed? A Comparison of Fast Versus Close in Getting Where You Want to Go in US Metropolitan Regions. Journal of the American Planning Association 78(2012): 157-172.

Levinson, D.M. Accessibility and the journey to work. Journal of Transport Geography 6 (1998): 11-21.

Litman, T.A. Sustainable Transportation Indicators: A Recommended Research Program For Developing Sustainable Transportation Indicators and Data. 2009.

Litman, T. The Hidden Traffic Safety Solution: Public Transportation. 2016.

Litman, T., and D. Burwell. Issues in Sustainable Transportation. International Journal of Global Environmental Issues, 6, no. 4 (2006): 331-347.

Malczewski, J. "GIS-based Multicriteria Decision Analysis: A Survey of the Literature." International Journal of Geographical Information Science 20 (2006): 703-726. http://doi.org/10.1080/13658810600661508

Malczewski, J., and C. Rinner. "Multicriteria Decision Analysis in Geographic Information Science." Advances in Geographic Information Science (2015). http://doi. org/10.1007/978-3-540-74757-4

Mihyeon Jeon, Christy, and Adjo Amekudzi. "Addressing Sustainability in Transportation Systems: Definitions, Indicators, and Metrics." Journal of infrastructure systems. 2005.

Moore, T., P. Thorsnes, and B. Appleyard. The Transportation/Land Use Connection (new ed.). American Planning Association (Planners Press), 2007.

NCHRP. A Guidebook for Sustainability Performance Measurement for Transportation Agencies. http://www.trb.org/Main/Blurbs/166313.aspx. 
North Carolina Sustainable Communities Task Force. Presentation to Board of Transportation's Joint Multimodal and Environmental Planning \& Policy Committees. May 4, 2011. http://ncdot.org/download/about/board/eppc/ documents/2011/201105 SCTF Presentation.pdf.

North Carolina (State). Department of Environment and Natural Resources. Sustainable Communities Initiative. http://www.onencnaturally.org/pages/SC SustainableCommunities.html.

Pei, Yi Lin, Adjo A. Amekudzi, Michael D. Meyer, Elise M. Barrella, and Catherine L. Ross. "Performance measurement frameworks and development of effective sustainable transport strategies and indicators." Transportation research record 2163, no. 1 (2010): 73-80.

Pennsylvania Department of Transportation and New Jersey Department of Transportation. Smart Transportation Guidebook: Planning and Designing Highways and Streets that Support Sustainable and Livable Communities. March 2008. http://www.state.nj.us/transportation/community/mobility/pdf/ smarttransportationguidebook2008.pdf.

Pohekar, S. D., and M. Ramachandran. "Application of Multi-Criteria Decision Making to Sustainable Energy Planning: A Review." Renewable and Sustainable Energy Reviews 8 (2004): 365-381. http://doi.org/10.1016/j.rser.2003.12.007

Pucher, J., J. Dill, and S. Handy. "Infrastructure, Programs, and Policies to Increase Bicycling: An International Review." Preventive Medicine 50 (2010): 106-125. Cited in Handy et al. [15] http://policy.rutgers.edu/faculty/pucher/Pucher Dill Handy10.pdf.

Reinke, David, and Daniel Malarkey. "Implementing Integrated Transportation Planning in Metropolitan Planning Organization: Procedural and Analytical Issues." Transportation Research Record 1552 (1996).

Riggs, W., 2018a. Technology, Civic Engagement and Street Science: Hacking the Future of Participatory Street Design in the Era of Self-Driving Cars (SSRN Scholarly Paper No. ID 3117731). Social Science Research Network, Rochester, NY.

Riggs, W., 2018b. Technology, Civic Engagement and Street Science: Hacking the Future of Participatory Street Design in the Era of Self-driving Cars. In Proceedings of the $19^{\text {th }}$ Annual International Conference on Digital Government Research: Governance in the Data Age, Dgo '18. ACM, New York, NY, 4:1-4:6.

Riggs, William. "Painting the fence: Social norms as economic incentives to nonautomotive travel behavior." Travel Behaviour and Society 7 (2017): 26-33.

Sallis, J.F., E. Cerin, T.L. Conway, M.A. Adams, L.D. Frank, M. Pratt, D. Salvo, J. 
Schipperijn, G. Smith, K.L. Cain, R. Davey, J. Kerr, P.-C. Lai, J. Mitáš, R. Reis, O.L. Sarmiento, G. Schofield, J. Troelsen, D.V. Dyck, I.D. Bourdeaudhuij, and N. Owen. The Lancet 387 (2016): 2207-2217.

Schlossberg, M., W.W. Riggs, A. Millard-Ball, and E. Shay. Rethinking the street in an era of driverless cars. 2018. UrbanismNext.

Sciara, Gian-Claudia, Susan Handy, and Marlon Boarnet. DRAFT Policy Brief on the Impacts of Pedestrian Strategies Based on a Review of the Empirical Literature. http://www.arb.ca.gov/cc/sb375/policies/ped/ped brief.pdf.

Solimar Research Group, Inc. South Bay Cities Mixed-Use Guidebook, Version 1.0. July 2007. http://www.southbaycities.org/files/Guidebook\%20Final\%20Draft\%207-1007 0.pdf.

Southworth, M., and E. Ben-Joseph. Streets and the Shaping of Towns and Cities. New York: McGraw-Hill, 1997. Cited in Handy et al. [16].

Spears, Steven, Marlon Boarnet, and Susan Handy. DRAFT Policy Brief on the Impacts of Land Use Mix Based on a Review of the Empirical Literature. http://arb.ca.gov/ cc/sb375/policies/mix/landusemix brief.pdf.

Spears, Steven, Marlon Boarnet, and Susan Handy. DRAFT Policy Brief on the Impacts of Parking Pricing Based on a Review of the Empirical Literature. http://www.arb. ca.gov/cc/sb375/policies/pricing/parkingpricing brief.pdf.

Spears, Steven, Marlon Boarnet, and Susan Handy. DRAFT Policy Brief on the Impacts of Road User Pricing Based on a Review of the Empirical Literature. http://www. arb.ca.gov/cc/sb375/policies/pricing/roadpricing brief.pdf.

Spears, Steven, Marlon Boarnet, and Susan Handy. DRAFT Policy Brief on the Impacts of Voluntary Travel Behavior Change Programs Based on a Review of the Empirical Literature. http://www.arb.ca.gov/cc/sb375/policies/vtbc/vtbc brief.pdf.

Spears, Steven, Marlon Boarnet, and Susan Handy. DRAFT Technical Background on the Impacts of Land Use Mix Based on a Review of the Empirical Literature. http:// arb.ca.gov/cc/sb375/policies/mix/landusemix bkgd.pdf.

Spears, Steven, Marlon Boarnet, and Susan Handy. DRAFT Technical Background Document on the Impacts of Parking Pricing Based on a Review of the Empirical Literature. http://www.arb.ca.gov/cc/sb375/policies/pricing/parkingpricing bkgd. pdf.

Spears, Steven, Marlon Boarnet, and Susan Handy. DRAFT Technical Background Document on the Impacts of Road User Pricing Based on a Review of the Empirical Literature. http://www.arb.ca.gov/cc/sb375/policies/pricing/roadpricing bkgd.pdf. 
Spears, Steven, Marlon Boarnet, and Susan Handy. DRAFT Technical Background Document on the Impacts of Voluntary Travel Behavior Change Programs Based on a Review of the Empirical Literature. http://www.arb.ca.gov/cc/sb375/policies/ vtbc/vtbc bkgd.pdf.

Steinitz, C. A Framework for Geodesign: Changing Geography By Design. Redlands, CA: ESRI Press, 2012.

Stimpson, J.P., F.A. Wilson, O.M. Araz, and J.A. Pagan. Share of mass transit miles traveled and reduced motor vehicle fatalities in major cities of the United States. Journal of Urban Health 91 (2014): 1136-1143.

Tal, Gil, Susan Handy, and Marlon G. Boarnet. DRAFT Policy Brief on the Impacts of Transit Access (Distance to Transit) Based on a Review of the Empirical Literature. http://www.arb.ca.gov/cc/sb375/policies/transitaccess/transitaccess brief.pdf.

Tal, Gil, Susan Handy, and Marlon G. Boarnet. DRAFT Technical Background Document on the Impacts of Transit Access (Distance to Transit) Based on a Review of the Empirical Literature. http://www.arb.ca.gov/cc/sb375/policies/transitaccess/ transitaccess bkgd.pdf.

Texas A\&M Transportation Institute. “Urban Mobility Report.” http://mobility.tamu.edu/ ums/.

US Department of Transportation, Federal Highway Administration. Statewide Opportunities for Integrating Operations, Safety and Multimodal Planning: A Reference Manual. May 2010. http://www.fhwa.dot.gov/planning/processes/ statewide/practices/manual/index.cfm.

US Department of Transportation, Federal Highway Administration. Transportation Planning for Sustainability Guidebook. January 2011. http://www.fhwa.dot. gov/environment/climate change/sustainability/resources and publications/ guidebook/index.cfm.

US Environmental Protection Agency. "Guide to Sustainable Transportation Performance Measures." August 2011. http://www.epa.gov/dced/transpo performance.htm.

US EPA, "Smart Growth." https://www.epa.gov/smartgrowth (accessed June 7, 2016).

Wagner, F., and R. Caves (eds.). Community Livability: Issues and Approaches to Sustaining the Well-Being of People and Communities. New York: Routledge, 2012.

Washington State Department of Transportation. Gray Notebook. http://www.wsdot. wa.gov/accountability/GrayNotebook.pdf. 
Washington State Department of Transportation. Performance Measurement Library. http://www.wsdot.wa.gov/Accountability/Publications/Library.htm.

Washington State Department of Transportation. WSDOT Accountability \& Performance Information. http://www.wsdot.wa.gov/Accountability/.

Zhou, J. Sustainable Transportation: Review of Proposals, Policies, and Programs 20002007. Transportation Research Board $88^{\text {th }}$ Annual Meeting. Washington, DC, Transportation Research Board. 2009.

Zietsman, J., and L. R. Rilett. Sustainable Transportation: Conceptualization and Performance Measures. Southwest Region University Transportation Center, 2002. 


\section{ABOUT THE AUTHORS}

\section{BRUCE APPLEYARD, PH.D.}

Dr. Appleyard is an Associate Professor of City Planning at San Diego State University (SDSU) and the Assistant Director of Active Transportation Research (ATR) where he helps people and agencies make more informed decisions about how we live, work, and thrive. Working from the human to regional/ecosystem scale, he is an author of numerous peerreviewed and professional publications, and is a renowned expert on urban quality, the future of transport, street livability and design for pedestrians and bicyclists. He also has expertise in coordinating housing, land use, and transport to help places become more sustainable, livable, and equitable. For more, see his online Smart Mobility Calculator https://smartmobilitycalculator.netlify.app/ - a planning support tool (PSTs) designed to help people take action to coordinate transport, housing, and climate action planning.

He recently served as a Guest Editor for the Special Issue celebrating 25 years of Transit Oriented Development (TOD) in the Journal of Planning Education \& Research, and just published Livable Streets 2.0 about the conflict, power, and promise of our streets.

https://www.elsevier.com/books/livable-streets-20/appleyard/978-0-12-816028-2

In 2006, The Robert Wood Johnson Foundation named Dr. Appleyard, alongside Barack Obama, as one of their Top Ten "Active Living Heroes" for his work helping communities.

Dr. Appleyard holds a Doctorate (as well as a Masters and Bachelors) from the University of California in the town of Berkeley where he grew up.

\section{JONATHAN STANTON}

Jonathan Stanton is a Master's of City Planning student at San Diego State University and a Student Worker for the County of San Diego in the Advance Planning division. Jonathan supports academic researchers at SDSU studying active transportation as well as land use planning and transportation planning, and he is currently focused on studying vehicle miles travelled (VMT) in the state of California. He completed a Bachelor's of Science from UC Davis in Environmental Policy Analysis and Planning, and has previously worked in the field of air quality testing, collecting and analyzing emissions data from stationary sources such as power generating plants, refineries, and cement plants.

\section{CHRIS ALLEN}

Chris is a PhD student in geography at San Diego State University, where he focuses on studying livability with GIS and machine learning methods. He also works as a data visualization product engineer at ESRI. 


\section{MTI BOARD OF TRUSTEES}

Founder, Honorable

Norman Mineta*

Secretary (ret.),

US Department of Transportation

\section{Chair,}

Abbas Mohaddes

President \& $\mathrm{COO}$

Econolite Group Inc.

\section{Vice Chair,}

\section{Will Kempton}

Executive Director

Sacramento Transportation Authority

\section{Executive Director,}

Karen Philbrick, PhD*

Mineta Transportation Institute

San José State University

\section{Winsome Bowen}

Chief Regional Transportation

Strategy

Facebook

\section{David Castagnetti}

\section{Co-Founder}

Mehlman Castagnetti

Rosen \& Thomas

\section{Maria Cino}

Vice President

America \& U.S. Government

Relations Hewlett-Packard Enterprise

\author{
Grace Crunican** \\ Owner \\ Crunican LLC
}

\section{Donna DeMartino \\ Managing Director \\ Los Angeles-San Diego-San Luis \\ Obispo Rail Corridor Agency}

\section{Nuria Fernandez**}

General Manager \& CEO

Santa Clara Valley

Transportation Authority (VTA)

\section{John Flaherty}

Senior Fellow

Silicon Valley American

Leadership Form

\section{William Flynn * \\ President \& CEO \\ Amtrak}

\section{Rose Guilbault}

Board Member

Peninsula Corridor

Joint Powers Board

Ian Jefferies*

President \& CEO

Association of American Railroads
Diane Woodend Jones

Principal \& Chair of Board

Lea + Elliott, Inc.

David S. Kim*

Secretary

California State Transportation

Agency (CALSTA)

\section{Therese McMillan}

Executive Director

Metropolitan Transportation

Commission (MTC)

\section{Bradley Mims}

President \& CEO

Conference of Minority

Transportation Officials (COMTO)

Jeff Morales

Managing Principal

InfraStrategies, LLC

Dan Moshavi, PhD*

Dean, Lucas College and

Graduate School of Business

San José State University

Toks Omishakin*

Director

California Department of

Transportation (Caltrans)
Takayoshi Oshima

Chairman \& CEO

Allied Telesis, Inc.

Paul Skoutelas*

President \& CEO

American Public Transportation

Association (APTA)

Beverley Swaim-Staley

President

Union Station Redevelopment

Corporation

Jim Tymon*

Executive Director

American Association of

State Highway and Transportation

Officials (AASHTO)

\section{Larry Willis*}

President

Transportation Trades

Dept.,AFL-CIO

$*$ = Ex-Officio

$* *=$ Past Chair, Board of Trustees

\section{Directors}

\section{Karen Philbrick, PhD}

Executive Director

\section{Hilary Nixon, PhD}

Deputy Executive Director

\section{Asha Weinstein Agrawal, PhD}

\section{Education Director}

National Transportation Finance

Center Director

\section{Brian Michael Jenkins}

National Transportation Security

Center Director

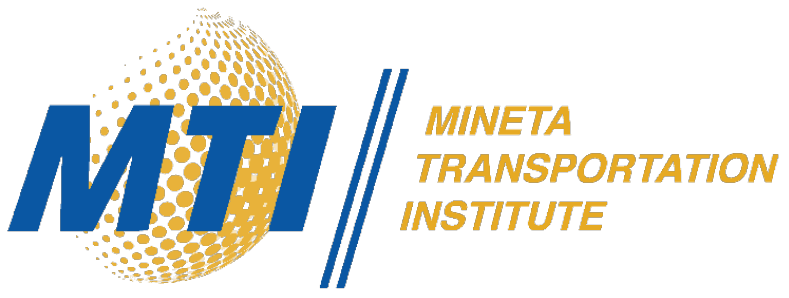

